\title{
The Role of Glycosphingolipids in Immune Cell Functions
}

\author{
Tao Zhang ${ }^{1 \dagger}$, Antonius A. de Waard ${ }^{2,3 \dagger}$, Manfred Wuhrer ${ }^{1 * \neq}$ and Robbert M. Spaapen ${ }^{2,3 * \neq}$ \\ ${ }^{1}$ Center for Proteomics and Metabolomics, Leiden University Medical Center, Leiden, Netherlands, ${ }^{2}$ Department of \\ Immunopathology, Sanquin Research, Amsterdam, Netherlands, ${ }^{3}$ Landsteiner Laboratory, Amsterdam UMC, University of \\ Amsterdam, Amsterdam, Netherlands
}

\section{OPEN ACCESS}

Edited by:

Monica M. Burdick

Ohio University, United States

Reviewed by:

Silvia Deaglio,

University of Turin, Italy

Amir M. Farnoud,

Ohio University, United States

*Correspondence:

Manfred Wuhrer

m.wuhrer@/umc.n

Robbert M. Spaapen

r.spaapen@sanquin.n

tThese authors have contributed equally to this work

¥These authors have contributed equally to this work

Specialty section:

This article was submitted to

T Cell Biology,

a section of the journal

Frontiers in Immunology

Received: 30 September 2018

Accepted: 14 January 2019

Published: 29 January 2019

Citation:

Zhang T, de Waard AA, Wuhrer $M$ and Spaapen RM (2019) The Role of Glycosphingolipids in Immune Cell Functions. Front. Immunol. 10:90. doi: 10.3389/fimmu.2019.00090
Glycosphingolipids (GSLs) exhibit a variety of functions in cellular differentiation and interaction. Also, they are known to play a role as receptors in pathogen invasion. A less well-explored feature is the role of GSLs in immune cell function which is the subject of this review article. Here we summarize knowledge on GSL expression patterns in different immune cells. We review the changes in GSL expression during immune cell development and differentiation, maturation, and activation. Furthermore, we review how immune cell GSLs impact membrane organization, molecular signaling, and trans-interactions in cellular cross-talk. Another aspect covered is the role of GSLs as targets of antibody-based immunity in cancer. We expect that recent advances in analytical and genome editing technologies will help in the coming years to further our knowledge on the role of GSLs as modulators of immune cell function.

Keywords: glycans, glycolipids, regulation, expression, immunity, differentiation, receptors, cancer

\section{INTRODUCTION}

The surface of cells is covered with glycans (or carbohydrates) that are part of glycoproteins, glycosaminoglycans, or glycosphingolipids (GSLs). GSLs consist of glycans conjugated to a lipid (ceramide) core and comprise a diverse group of over 300 different complex molecules based on variation in the glycan buildup (1-3). The diversity of glycan structures on GSLs is directed by a range of proteins involved in glycan biosynthesis including glycosyltransferases (GTs), glycosidases, enzymes involved in glycan precursor biosynthesis and nucleotide sugar transporters. These proteins are differentially expressed throughout the immune system giving rise to a large variability in GSL expression patterns which suggests a functional role for GSLs in immune cell development or activation (4). GSLs are essential parts of GSL enriched microdomains (GEMs) in the cell membrane, which have an important role in molecular signaling, cellular cross-talk, and cell adhesion (5-7). Consequently, mice deficient in subclasses of GSLs show immunological, reproductive, neuronal, renal, gastrointestinal, and metabolic defects (8). To date, cell surface GSLs have been shown to be involved in diverse immune processes, including differentiation, immune recognition, and transduction of activation signals. In this review, we summarize the literature on GSL expression of various immune cells and highlight the functions that have been attributed to these GSLs. 


\section{BIOSYNTHESIS AND EXPRESSION OF GSLS IN NAÏVE AND DIFFERENTIATED IMMUNE CELLS}

GSLs are divided into two groups based on the presence of a galactosylated or glucosylated ceramide (Cer) core. The latter group consists of complex structures subdivided into gangliosides, (iso)globosides, and (neo)lacto-series GSLs (Figure 1A; Table S1). The GTs UDP-glucose ceramide glucosyltransferase (UGCG) and $\beta 1,4$-galactosyltransferase $5 / 6$ (B4GALT5/6) synthesize glucosylceramide (GlcCer) and lactosylceramide (LacCer) respectively, forming the precursor of GlcCer-based GSLs (8). GSLs are further divided into four major series based on the synthesis pathways (Figure 1A). Alpha2,3-sialyltransferase 5 (ST3GAL5) is the key enzyme for the synthesis of GM3, which is the parent structure for $a-, b$-, and $c$-series gangliosides. $\beta 1,4-N$ acetylgalactosaminyltransferase 1 (B4GALNT1) catalyzes the generation of asialo GM2 by transferring $N$-acetylgalactosamine (GalNAc) to LacCer, initializing the synthesis of $o$-series gangliosides. Lactotriaosylceramide (Lc3) is the starting structure for synthesis of (neo)lacto-series GSLs, which is synthesized by $\beta 1,3-N$-acetylglucosaminyltransferase 5 (B3GNT5). The (iso)globosides globotriaosylceramide (Gb3) and isoglobotriaosylceramide (isoGb3) are generated by the addition of a galactose to LacCer in $\alpha 1,4$ and $\alpha 1,3$ linkages by $\alpha 1,4-$ galactosyltransferase (A4GALT) and $\alpha 1,3$-galactosyltransferase 2 (A3GALT2) respectively (Figure 1A). Further extension and modifications of these core structures, including elongation, sulfation, and sialic acid acetylation, contributes to the diversity of the repertoire expressed in (immune) cells (9-13).

The GSL repertoire of different immune cells varies per cell type under physiological conditions (14-16). The expression of some GSLs on immune subsets is well-studied, and antibodies against them have found their way into the cluster of differentiation (CD) marker set established decades ago.

\footnotetext{
Abbreviations: GSL, glycosphingolipid; GT, glycosyltransferase; GEMs, glycosphingolipid enriched microdomains; Cer, ceramide; UGCG, UDPglucose ceramide glycosyltransferase; B4GALT, $\beta 1,4$-galactosyltransferase; GlcCer, glucosylceramide; LacCer, lactosylceramide; ST3GAL, $\alpha 2,3$ sialyltransferase; B4GALNT1, $\beta 1,4-N$-acetylgalactosaminyltransferase 1; GalNAc, $\mathrm{N}$-acetylgalactosamine; Lc3, lactotriaosylceramide; Gb3, globotriaosylceramide; isoGb3, isoglobotriaosylceramide; B3GNT, $\beta 1,3-N$-acetylglucosaminyltransferase; A4GALT, $\alpha$ 1,4-galactosyltransferase; A3GALT2, $\alpha 1$,3-galactosyltransferase 2; CD, cluster of differentiation; CTB, cholera toxin subunit B; BMMCs, bone marrow culture-derived mast cells; SMCs, serosal mast cells; PMA, phorbol myristate acetate; Le ${ }^{\mathrm{x}}$, Lewis $\mathrm{X}$ structures, Gal $\beta 1-4$ (Fuc $\left.\alpha 1-3\right)$ GlcNAc $\beta 1-; \quad S(3) n L c 4$, Neu5Aca2-3nLc4; S(6)nLc4, Neu5Aca2-6nLc4; S(3)nLc6, Neu5Aca2-3nLc6; moDCs, monocyte-derived dendritic cells; Gal $\alpha 1-3(\mathrm{~F}(2))$ ASGM1, Gal $\alpha 1-3$ (Fuc $\alpha 1$ 2)asialoGM1; Fo, Forssman glycolipid antigen, GalNAc $\alpha 1-3 \mathrm{~Gb} 4$; BMDCs, bone marrow-derived dendritic cells; NKT, natural killer T; NK, natural killer; NeuGc, $N$-glycolylneuraminic acid; LacNAc-GM1, Gal $\beta 1-4$ GlcNAc $\beta 1-3 G M 1$; Gal $\alpha 1$ 3LacNAc-GM1, S(3)LacNAc-GM1， Neu5Ac $\alpha 2-3$ Gal $\beta 1-4 G l c N A c \beta 1-3 G M 1 a ;$ IL, interleukin; IFN- $\alpha$, Interferon- $\alpha$; TNF- $\alpha$, tumor necrosis factor- $\alpha$; LPS, lipopolysaccharide; TCR, T cell receptor; LXR, liver X receptor; ST, shiga toxin; STb, B subunit of ST; PCI, protein-carbohydrate interaction; CCI, carbohydratecarbohydrate interaction; EGFR, epidermal growth factor receptor; CAR, chimeric antigen receptor; TLR4-MD2, Toll-Like Receptor 4-myeloid differentiation factor 2; EtxB, enterotoxin subunit B; HIV, human immunodeficiency virus; STb, B subunit of ST; NBDNJ, N-butyl 1-deoxynojirimycin. Glycan abbreviations and structures are listed in Table S1.
}

At that time, it was not yet known that these antibodies recognized glycan headgroups of GSLs, and therefore they have been assigned a specific $\mathrm{CD}$-number. This group includes CD15, CD17, CD60, CD65, CD75, CD77, CD173, and CD174 (Figures 1A,B), some of which are still being used to phenotype and isolate immune cell subpopulations (17). For example, CD77 represents the $\mathrm{Gb} 3$ structure, which has been employed to define a B cell subpopulation. Notably, the specific terminal glycan motifs of CD15, CD75, CD173, and CD174, can be carried by GSLs and glycoproteins. In the following sections, we summarize current knowledge on GSL expression patterns in different immune cell subsets (see Figure $\mathbf{2}$ and Table $\mathbf{1}$ for an overview).

\section{Hematopoietic Stem and Progenitor Cells}

HSCs are multipotent cells located in bone marrow which can differentiate into myeloid and lymphoid progenitor cells (Figure 2). To date, the GSL content of HSCs has hardly been studied, probably due to the low abundance of HSCs in blood and bone marrow and the difficulty to isolate them (75). Some studies suggest the presence of GM1 on HSCs based on binding of Cholera Toxin B (CTB). However, this glycan-binding subunit $B$ of cholera toxin has a broader specificity then just GM1 (discussed in section Organization of Membrane Microdomains) (76-78). Furthermore, Giebel et al. found that GM3 is expressed and localized at the leading edge of polarized $\mathrm{CD} 34^{+} \mathrm{HSCs}$, suggesting a role for GM3 GEMs in the polarization of HSCs (18). With respect to neutral GSLs, Gb5 was detected after exposure to fetal calf serum (19), but not on freshly isolated HSCs, even not as a sialylated or fucosylated variant. This finding is supported by a lack of expression of the relevant GTs in HSCs. Thus, environmental factors may change the expression of GTs, which has to be kept in mind when evaluating GSL expression on cultured or stimulated cells. In addition, CD173 and CD174 (Figure 1B), which may be carried by GSLs, are found to be specifically expressed on naïve CD34 ${ }^{+}$HSCs and disappear after differentiation (79).

In human myeloid progenitors-which give rise to mast cells, granulocytes, monocytes, and bone marrow-derived dendritic cells-GlcCer, LacCer, gangliosides (GM2, GM3, and GD3), and globosides (Gb3 and $\mathrm{Gb} 4$ ) are reported (Figure 2). In some studies, (neo)lacto-series GSLs (Lc3 and nLc4) were also weakly detected $(20,23)$. The mouse myeloid progenitor cell line FDCP1 displays LacCer, gangliosides (GM1, GM2, GM3, GD1a, GD1b, and GD3), and globoside Gb3, while no GlcCer or (neo)lacto-series GSLs were detected (24). This work further revealed that GM1 and GD1a are the two major gangliosides accumulated by FDC-P1 cells. Reports on GSL expression of lymphoid progenitors, the precursors of $\mathrm{NK}, \mathrm{T}$ and $\mathrm{B}$ cells, are absent in literature. We can conclude that gangliosides are expressed in HSCs and progenitor cells, while globosides and (neo)lacto-series GSLs are hardly expressed in HSCs, and at relatively low levels during further differentiation.

\section{Myeloid Cells}

Myeloid cells have been studied for decades and express some unique GSLs. The best described myeloid-specific GSL is a fucosylated neolacto-series GSL which is known as the CD65 antigen (Figure 1B) (80-82). It is expressed on most myeloid 


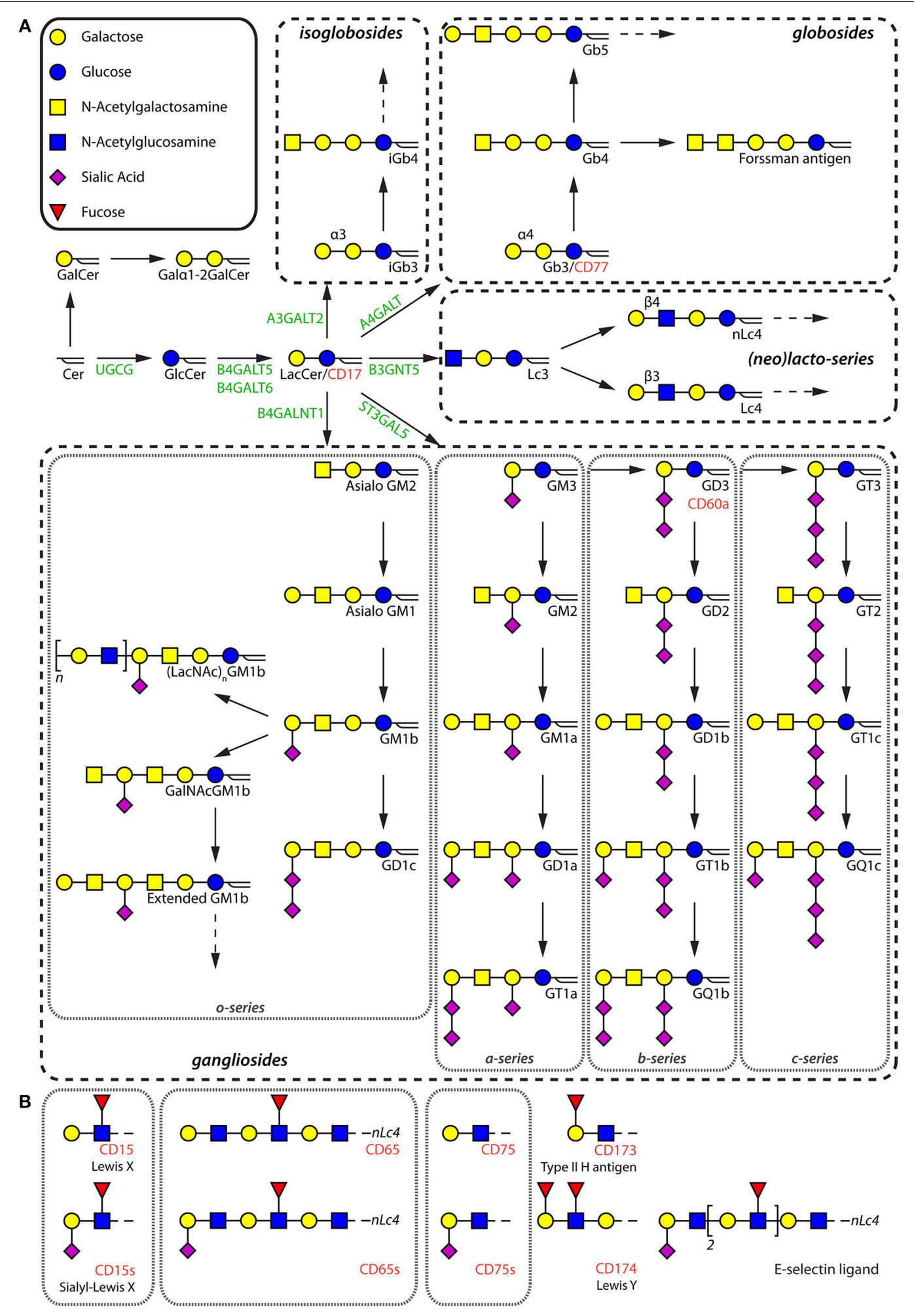

FIGURE 1 | Schematic diagram of the different types of GSLs. (A) Major GSLs expressed in immune cells and proposed GSL biosynthetic pathway. The key enzymes are in green. GSLs that have been given a cluster of differentiation (CD) number are annotated in red. (B) Terminal glycan motifs that have been given a CD number and the most prominent E-selectin ligand present on human neutrophils. 


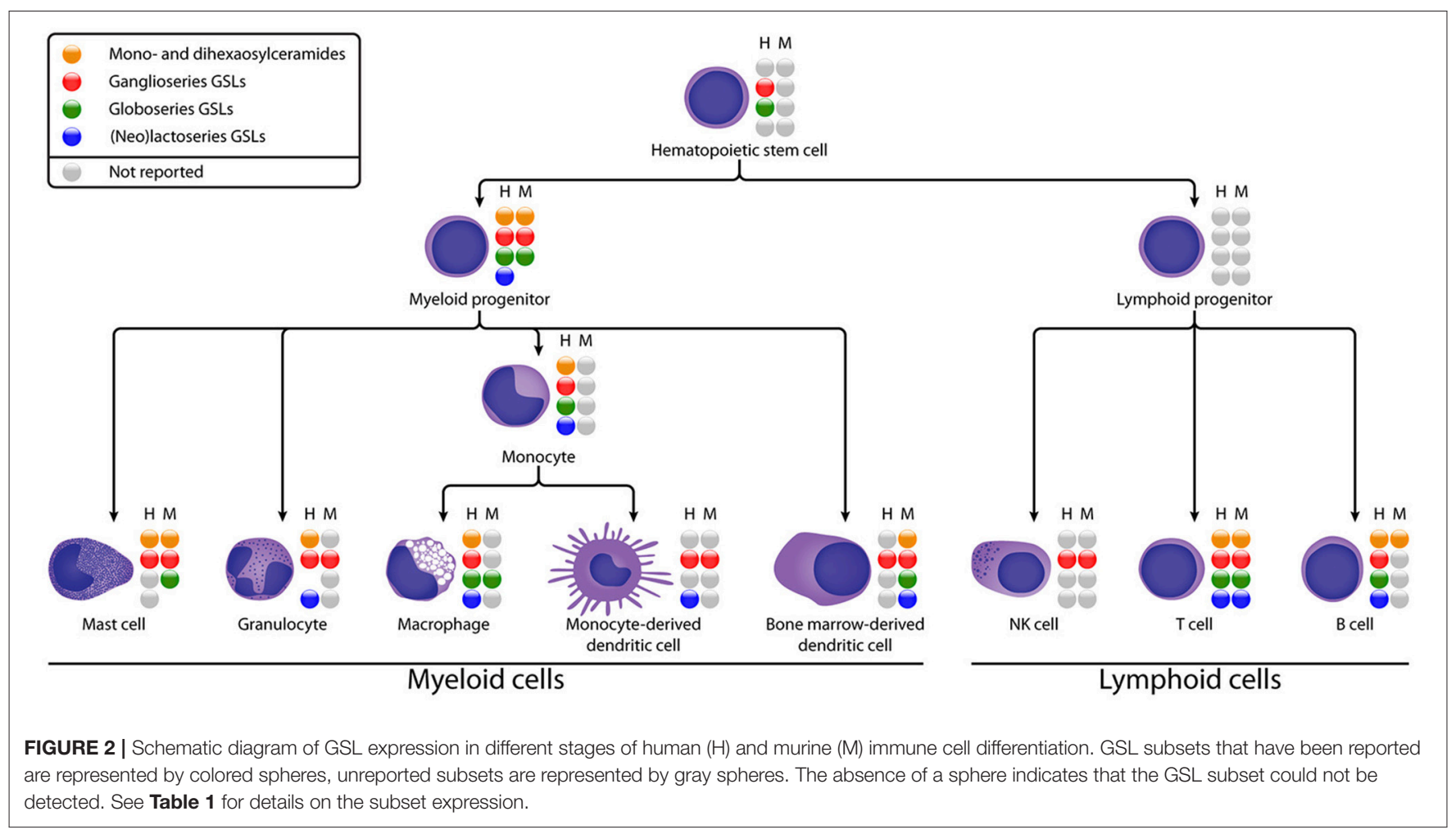

cells during development, highly on granulocytes and weakly on monocytes in peripheral blood. The sialylated form of CD65 (CD65s) is expressed when the myeloid progenitor antigen CD34 disappears, indicating that CD65s expression marks a turning point in myeloid cell differentiation. In addition to CD65 and CD65s, the expression patterns of other GSLs in mast cells, granulocytes, monocytes, macrophages, and DCs will be discussed in the following sections (Figure 2).

\section{Mast Cells}

After development from bone marrow-derived progenitor cells, mast cells can circulate as $\mathrm{CD} 34^{+}$progenitor cells, or migrate into tissues to differentiate into mature mast cells under the influence of cytokines.

It is well-recognized that GD3 is the most abundantly expressed GSL on the surface of nearly all mast cells (26). Zuberbier et al. studied the alterations of ganglioside expression during maturation of the human mast cell line HMC-1. Upon differentiation, a highly elevated expression of GM3 and GM3-derived $a$-series gangliosides (Figure 1A), including GM2, GM1a, and GD1a, were observed as a result of upregulation of the GTs ST3GAL5, B4GALNT1, ST8SIA1, and ST3GAL2 (25). Similarly, mouse serosal mast cells (SMCs) mainly express GM3. The ability to synthesize complex acidic GSLs is possibly lost during mast cell maturation, because in vitro differentiated bone marrow-derived mast cells (BMMCs) expressed-next to GM3-GM1, which was lost when matured toward SMC-like cells $(29,30)$.

Neutral GSLs have not been biochemically analyzed in human mast cells, except for the observation of LacCer in HMC1 cells (25). For the murine BMMCs, expression of GlcCer,
LacCer, asialo GM1, Gb3, and Gb4 has been described, while no (neo)lacto-series GSLs have been reported $(27,28,83,84)$. Interestingly, specifically Gb4 was found to be expressed in secretory granules, where it may have a yet unknown function (28). During in vitro activation of BMMCs, surface expression levels of Gb4 increased, which is thought to be the result of the fusion of internal membranes with the plasma membrane (28). Intriguingly, the Forssman glycolipid antigen (Fo), GalNAc $\alpha 1$ $3 \mathrm{~Gb} 4$, is specifically expressed by SMCs and not by BMMCs (27). In contrast to murine cells, only Gb5, but not LacCer, Gb3 or Gb4, was found on rat SMCs (85).

\section{Granulocytes}

Neutrophils, eosinophils, and basophils are granulocytes derived from myeloid precursor cells and have similar characteristics and functions in innate immune responses.

Human neutrophils are rich in GSLs, and around $2 \mathrm{mg}$ of GSLs can be extracted from $10^{10}$ cells. Detailed structural characterization of these GSLs showed neutrophils contain a very complex ganglioside mixture $(34,37,86,87)$. Similar to BMMCs, GM1 and GM3 are the most abundant gangliosides in neutrophils. Compared to other bone marrow-derived cells, mature neutrophils were found to express the highest levels of GM1 $(32,35,87)$. Later studies revealed that the presence of GM1 is related to the stage of neutrophil apoptosis, allowing the use of GM1 as an aging marker for neutrophils (40). In contrast to mast cells, neutrophils were not found to express GD3 (34).

With respect to neutral GSLs, human neutrophils express GlcCer, LacCer, and a set of (neo)lacto-series GSLs, but no globoside has been detected $(23,31-33,35,39,88)$. During differentiation of the promyelocyte cell line HL60 toward 
TABLE 1 | GSL expression in human and murine immune cells.

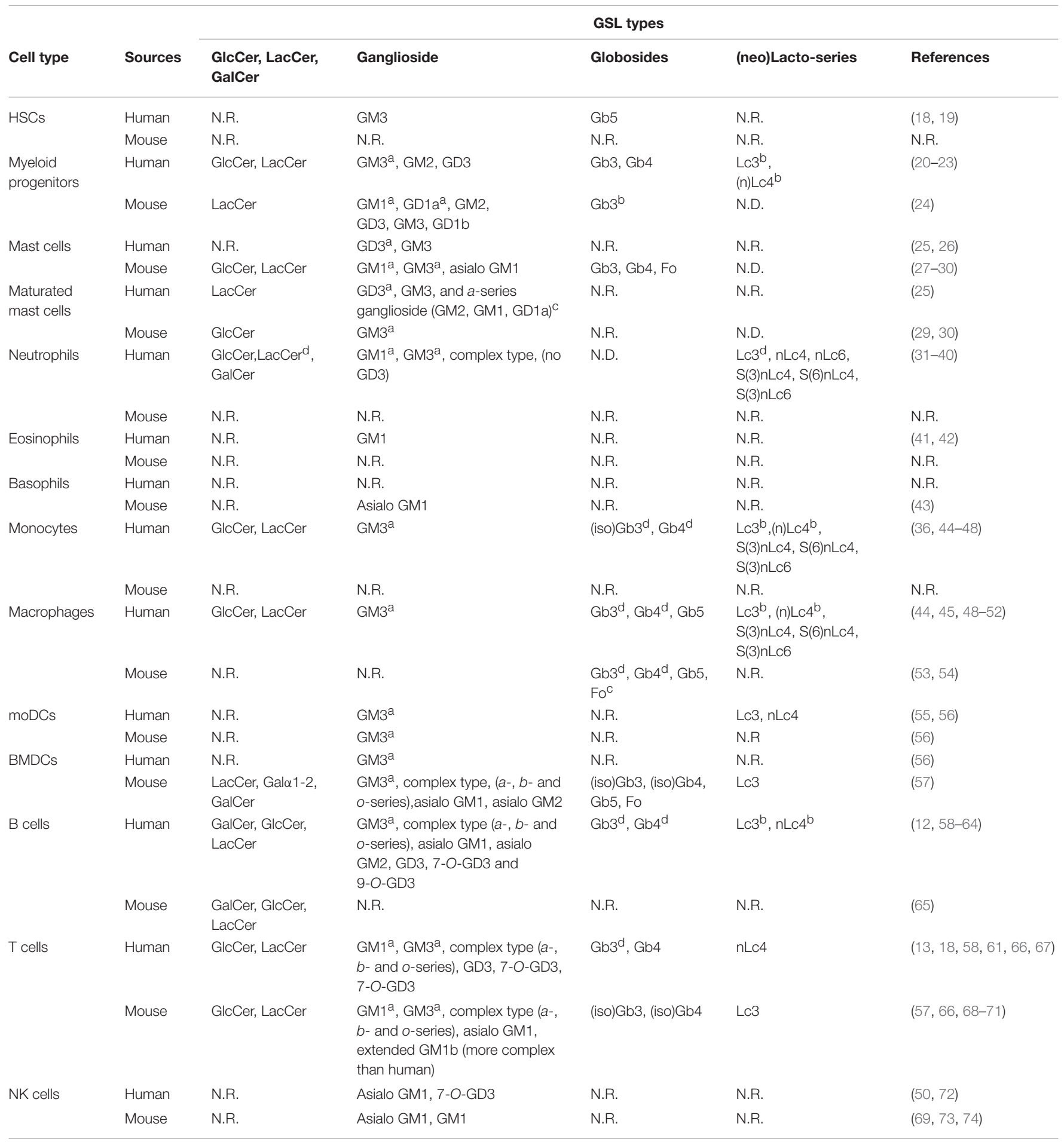

N.R., Not reported; N.D., Not detected; ${ }^{a}$ Dominant abundance; ${ }^{b}$ Low abundance; ${ }^{c}$ Specific expression; ${ }^{d}$ Dominant abundance among neutral GSLs.

granulocytes using all-trans retinoic acid or phorbol myristate acetate (PMA), the (neo)lacto-series synthase B3GNT5 was upregulated $(21,89)$. Therefore, Lc3, after LacCer, appeared to be the predominant species accounting for about $10 \%$ of the total neutral GSL fraction $(38,90)$. Notably, the neolacto-series
GSLs are the major class in neutrophils, containing Lc3, nLc4, nLc6, and $a$-series of GSLs carrying $\mathrm{Le}^{\mathrm{x}}$ (Lewis $\mathrm{X}$ structures, Gal $\beta 1-4$ (Fuc $\alpha 1-3)$ GlcNAc $\beta 1-)$, also known as CD15 (Figure 1B) $(35,38)$. In addition, sialylated neolacto-series GSLs (S(3)nLc4, $\mathrm{S}(6) \mathrm{nLc4}$, and $\mathrm{S}(3) \mathrm{nLc6})$ have also been detected $(33,91)$. The 
unique expression of these neolacto-series GSLs by neutrophils in comparison to other immune cells may be required to interact with pathogens or the humoral immune system.

To date, there are hardly any studies on the GSL expression of eosinophil and basophils. Ganglioside GM1 has been detected at the surface of eosinophils, and a stepwise upregulated expression was observed during cell differentiation from the promyelocyte to the eosinophil stage $(41,42)$. For murine basophils, a high level of asialo GM1 expression has been described (43).

\section{Monocytes, Macrophages, and Dendritic Cells}

Monocytes, macrophages, and dendritic cells (DCs) are phagocytic innate immune cells, which drive adaptive immune responses via antigen processing and presentation (92, 93). Monocytes can differentiate in vitro into macrophages or monocyte-derived DCs (moDCs) after specific cytokine stimulation. All monocytes, macrophages, and moDCs express high levels of GM3 in both human and mouse $(49,94,95)$. Cultured human macrophages yield approximately seven times more GM3 per million cells than ex vivo peripheral blood monocytes (2.7 vs. $0.4 \mu \mathrm{g}$ respectively) (46). Accordingly, such macrophages, but also in vitro differentiated moDC express 10-fold higher ST3GAL5 levels compared to freshly isolated monocytes $(46,55,56,96)$. Interestingly, the high expression of acidic GSLs is probably in part also facilitated by a decreased expression of $\alpha 2,3$ - and $\alpha 2,6$-sialidases (such as NEU3), which was for example observed in PMA-differentiated THP-1 macrophages $(97,98)$. Similar to humans and mice, rat abdominal macrophages express GM3 as the predominant acidic GSLs, followed by GM2 (85).

Monocytes and macrophages seem to have a different neutral GSL composition compared to other human myeloid immune cells since they express globosides ((iso)Gb3 and Gb4) as the major neutral GSLs $(36,44,45,48,52)$. Neolacto-series GSLs such as Lc3 and $\mathrm{nLc} 4$ are also detectable and upregulated during differentiation toward moDCs, but are reduced during differentiation toward macrophages as a result of decreased B3GNT5 gene expression $(36,44,45,55,96)$. Additionally, during macrophage differentiation the expression of Gb5 is upregulated, which-like Gb3-is a target for the human immunodeficiency virus (HIV) gp120 glycoprotein $(94,99)$. In mouse abdominal macrophages, it has been demonstrated that neutral GSLs are expressed at higher levels than gangliosides. Asialo GM1 was specifically expressed after a 3-day culture, but its expression gradually declined after prolonged cultures. Other neutral GSLs including GlcCer and Gb3 were highly upregulated in macrophage differentiated murine M1 cells (100-102). Fo GSLs are expressed in mature mouse macrophages and increases during the lifetime of the cell. It is used as a differentiation marker and is specifically expressed in defined areas in spleen, lymph nodes, and bone marrow, which suggests it may have a function in lymphoid organ homing or residency $(53,54,103-105)$. In addition to the globosides $\mathrm{Gb} 3, \mathrm{~Gb} 4$, and Gb5, the specific neutral GSL Gal $\alpha 1-3(\mathrm{~F}(2))$ ASGM1 was also found to be highly expressed in rat macrophages (85).

During differentiation of murine bone marrow precursors to bone marrow-derived DCs (BMDCs), no significant change in acidic GSLs nor LacCer or asialo GM1 content was found, even though $a$-series (GM1a, GD1a, and GT1a), $b$-series (GD3, GD1b, and GT1b), and $o$-series (asialo GM1 and GM1b) are generally present in BMDCs (57). However, Lc3, Gb3, Gb4, and Fo GSLs were found to be more abundant on mature BMDCs. Interestingly, $\mathrm{Li}$ et al., also described the presence of isoGb3 and isoGb4 to be enhanced in mature BMDC. Though the isoGb3 expression level was very low compared to Gb3, $\sim 0.8 \%$ in both immature and mature DCs. IsoGb3 can be specifically recognized in the context of CD1d by mouse $\mathrm{V} \alpha 14$ and human $\mathrm{V} \alpha 24$ natural killer $\mathrm{T}(\mathrm{NKT})$ cells, and plays an important role in regulating NKT cell responses during infections, cancer and autoimmunity (47, 57, 106-108). In addition, a unique Gal $\alpha 1-2 \mathrm{GalCer}$ was found in BMDC as well, which can be processed to GalCer for presentation to NKT cells (109). Based on the upregulation of globosides during the differentiation of macrophages, moDCs and BMDCs, globosides function as markers of differentiation (57).

\section{Lymphocytes}

Lymphocytes include T cells, B cells, and natural killer (NK) cells (Figure 2), which are the main adaptive and innate immune effector cells. GSL expression in $\mathrm{B}$ and $\mathrm{T}$ cells has been widely studied during differentiation, maturation, and immune responses.

\section{B Cells}

After antigen exposure, B cells can differentiate into plasma cells secreting antibodies to clear antigen-bearing entities. Human pre-B cells have a similar GSL-profile to cells of myeloid origin. Human B cells mainly express GM3, but also more complex gangliosides such as GM1, GD1a, GD1b, and GT1 (32, 58, 63). In addition, asialo GM1 and asialo GM2 are expressed in minor amounts (61). Notably, ganglioside GD3 and its $O$-acetylated variants, $7-O-G D 3$ and $9-O-G D 3$ (CD60b and $\mathrm{CD} 60 \mathrm{c}$, respectively), have been described to be expressed on $\mathrm{B}$ cells (and also $\mathrm{T}$ cells) although the expression levels vary $(12,50,72)$. Some of these studies propose an involvement of $\mathrm{O}$-acetylated gangliosides in lymphocyte activation processes. Mouse B cells show an even higher expression of the gangliosides GM1 and GM3 and their derivatives compared to human B cells. Interestingly, whereas humans are incapable of synthesizing $N$-glycolylneuraminic acid (NeuGc), gangliosides GM1 and GM3 modified with this sugar are present on mouse B cells. Importantly, the CD22 ligand Neu5Aca2-6Gal-, also known as CD75 (Figure 1B), was identified as a major B lymphocyte epitope (95). Additionally, rat B cells lowly expressed Gal $\alpha 1$ 3(F(2))ASGM1 and some unique extended GM1b structures, which contain the GM1b core extended with LacNAc unit(s), including Gal $\alpha 1-3$ LacNAc-GM1, Gal $\alpha 1-3(\mathrm{LacNAc})_{2}-\mathrm{GM} 1$, and S(3)LacNAc-GM1 (110).

Both human and murine B cells express GalCer, GlcCer, LacCer, and globosides, but only immature B cells contain (neo)lacto-series GSLs since activated B cells lack expression of the Lc3 synthase B3GNT5 $(23,63,65,66)$. Human peripheral B cells contain relatively large amounts of more complex globosides which are nearly absent in tonsillar B lymphocytes $(32,62)$. 
Importantly, Gb3 (CD77) was initially found to be specifically expressed by germinal center B cells $(60,111)$. However, it was later identified that not all germinal center B cells express Gb3 (112). In contrast to peripheral and germinal center B cells, GlcCer, and LacCer comprise the largest portion of GSLs in tonsillar B lymphocytes. In addition, Gb3 expression increased 10 -fold in a bovine B cell lymphoma cell line after stimulation with different mitogens, suggesting that $\mathrm{B}$ cells actively regulate surface expression of Gb3 (113).

Human B cell differentiation and activation are accompanied by sequential regulation of GSL expression via modulation of the corresponding GTs $(61,63,114)$. GM3 synthase B4GALNT1 is differentially activated from the pre-B cell stage to the terminally differentiated myeloma (plasma)cells, and GM2 synthase B4GALT has a high activity in lymphoblastoid cell lines and terminally differentiated myeloma cells only. Lc3 synthase B3GNT5 shows a high activity in pro- and pre-B cells, initializing the synthesis of (neo)lacto-series GSLs. But, (neo)lacto-series synthesis is shut down in more differentiated cells. For the expression of globosides, Gb3 synthase A4GALT and Gb4 synthase B3GALNT are only activated in the late stages of B cell differentiation (114). These results explain the stagedependent expression of GSLs like Gb3, Gb4, GM2, and GM3, suggesting functional roles of GSLs during B cell maturation (63).

\section{T Cells}

$\mathrm{T}$ cells are the effector cells of adaptive immunity through the production of various cytokines and the activation-induced cell death. Variations in GSL expression have been related to T cell subtype, activation, differentiation, and function $(66,67)$. Human T cells express both GM1 and GM3, which are clustered in GEMs and thought to be involved in T cell activation (66). Besides these two gangliosides, also minor levels of other gangliosides (GD1a, GD1b, GT1b etc.) have been detected $(18,115,116)$. During interleukin-2 (IL-2) stimulation, $\mathrm{CD}^{+}{ }^{+} \mathrm{T}$ cells, more than $\mathrm{CD} 4^{+}$ T cells, upregulate GM1 expression $(117,118)$. In contrast, naïve $\mathrm{CD}^{+} \mathrm{T}$ cells stimulated with anti-CD3/CD28 show increased expression of ST8SIA1, driving GD3 expression (119). Similar to $\mathrm{B}$ cells, $\mathrm{O}$-acetylated variants of the ganglioside GD3 have been described to be expressed by human $\mathrm{T}$ cells $(10,12,13,50)$. Desialylation of GSLs was also apparent in $\mathrm{T}$ cells, since the sialidases NEU1 and NEU3 are 2- to 3-fold upregulated upon $\mathrm{T}$ cell receptor (TCR) ligation of both $\mathrm{CD} 4^{+}$and $\mathrm{CD} 8^{+} \mathrm{T}$ cells. Interestingly, inhibition of these sialidases resulted in a greater amount of cell surface sialic acids, but also a reduced IFN- $\gamma$ secretion upon activation of T cells $(120,121)$. These data indicate that $\mathrm{T}$ cell effector function can be modulated by sialic acid bearing GSLs in T cells.

Similar to human $\mathrm{T}$ cells, murine $\mathrm{T}$ cells express GM3, GM1a, GM1b, GD1b, GD1c, GD3, asialo GM1, and extended GM1b series. Compared to $\mathrm{CD}^{+} \mathrm{T}$ cells, murine $\mathrm{CD} 4^{+} \mathrm{T}$ cells express higher level of ST3GAL5 to synthesize $a$ - and $b$-series gangliosides (GM1a and GD1b). In contrast, $\mathrm{CD}^{+} \mathrm{T}$ cells express more B4GALNT1, resulting in higher levels of $o$-series gangliosides (asialo GM1, GM1b, GalNAcGM1b, and extendedGM1b) (66, 68, 70, 71, 122-126). Although these studies show that stimulation of $\mathrm{T}$ cells correlates with elongation of a common
GM1b precursor structure, it is as yet unclear how such GSLs contribute to $\mathrm{T}$ cell physiology.

The total amount of gangliosides per cell was found to be about 10 -fold higher in mature $\mathrm{T}$ cells than in thymocytes. This increased level of ganglioside expression mainly resulted from the upregulation of GM1 subclasses and $o$-series gangliosides (GalNAcGM1b and extended-GM1b) in T cells whereas GD1b is downregulated $(70,71)$. This distinct expression of gangliosides between murine thymocytes and mature $\mathrm{T}$ cells suggest a stage and type-dependent expression of gangliosides, similar to B cells (71). Notably, whereas GD1c is highly expressed in both thymocytes and $\mathrm{CD}^{+}{ }^{+} \mathrm{T}$ cells, $\mathrm{CD} 8^{+} \mathrm{T}$ cells downregulate its expression $(68,116,127)$. Similarly, GM1a is present on both thymocytes and $\mathrm{CD}^{+} \mathrm{T}$ cells, while only trace amounts are found in $\mathrm{CD}^{+} \mathrm{T}$ cells (70). Compared to the human $\mathrm{T}$ cells, activated murine $\mathrm{CD}^{+} \mathrm{T}$ cells also upregulate the sialidase NEU3 and downregulate NEU1 (128). In addition, some unique modified GM1 series, including Gal $\alpha 1-3$ LacNAc-GM1, Gal $\alpha 1-$ 3 (LacNAc) 2 -GM1, and S(3)LacNAc-GM1 were found in rat thymocytes $(110,129)$.

With respect to neutral GSLs, both human and murine T cells express GlcCer, LacCer, asialo GM1, globosides, and (neo)lactoseries $(57,58,67,71)$. In murine and rat $\mathrm{T}$ cells, quantification of neutral GSLs has revealed that the amount of neutral GSLs was higher in peripheral $\mathrm{T}$ cells compared to thymocytes. The major neutral GSLs in thymocytes are globosides while asialo GM1 is the most abundant neutral GSL in mature T cells $(58,69$, $130,131)$. In addition, some unique neutral GSLs, such as Gal $\alpha 1$ $3(\mathrm{~F}(2))$ ASGM1, have been detected in rat thymocytes (110). The presence of isoGb3 on $\mathrm{T}$ cells was recently described, which is recognized by both mouse and human NKT cells when presented by CD1d (57). However, the relevance of this GSL for NKT cells remains to be elucidated since mice that lack the isoGb3 synthesis machinery show a normal phenotype and function (47).

\section{NK Cells}

NK cells develop in bone marrow and account for up to $15 \%$ of peripheral blood mononuclear cells. NK cell activity is unleashed by a loss of inhibitory signaling of their receptors that recognize MHC class I on a target's cell surface, which often is the case on infected or malignant cells.

To date, the GSL expression on NK cells has not been wellstudied. In contrast to NK cell precursors, mature NK cells express asialo GM1 $(69,73,74,80)$. Besides asialo GM1, NK cells in mice have been reported to express GM1 at a relatively high level compared to splenic T cells (69). The ganglioside 7-O-acetyl GD3 was found at medium levels in $16 \%$ of the $\mathrm{CD}_{16}{ }^{+} \mathrm{NK}$ cells $(50,72)$.

\section{Considerations Concerning GSL Expression Analyses}

Many studies have contributed to the current knowledge of GSL expression in immune cells, during development, maturation, or activation. Still, information on GSL subtype expression in several immune cell subsets is incomplete (Table $\mathbf{1}$ and Figure 2) and in many cases lack structural details, often due to the limitations of the analytical tools employed. Incomplete 
structural information poses a challenge in understanding expression, regulation, and function of GSLs in immune cells. Thus, further in depth structural studies are pivotal as a basis for functional investigations.

It is clear though that the subtypes of GSLs are very differentially expressed throughout the immune system, suggesting that GSLs not just constitute a structural requirement for membrane integrity of immune cells but rather play specific roles in their function. For example, (neo)lacto-series GSLs are highly expressed by neutrophils, but not their progenitor cells, suggesting a specific role in neutrophil mediated immunity. This may relate to pathogen recognition through an interaction of neolacto glycans with pathogen-expressed proteins (132). On the other hand, it is curious that the expression of some GSLs by human immune cells significantly differs from their murine counterparts. Does this mean that GSLs are functionally dispensable or at least replaceable? A few functions of GSLs have been identified and will be discussed below. Furthermore, GSL expression alterations in response to cytokines and other modulators have also been observed, suggesting an intricate regulation of synthesis and degradation which will be discussed in the next chapter.

\section{REGULATION OF GSL EXPRESSION IN IMMUNE CELLS}

Differentiation and activation of immune cells leads to alterations in the GSL repertoire, likely through modulation of the expression of GTs, glycosidases, glycan precursor synthesizing enzymes, and nucleotide sugar transporters (Figure 3) (1416). Although these processes are well-documented, little information is available on the regulation of GSL expression in immune cells specifically. Nevertheless, the GSL regulation in the context of immune cell differentiation and activation as described in Biosynthesis and Expression of GSLs in Naïve and Differentiated Immune Cells, is often regulated by well-known signals, such as cytokines. We will now further focus on the molecular details of such external signals on the regulation of GSL synthesis and expression in immune cells.

\section{Regulation of GSL Expression by Cytokines}

It is yet largely unclear what the intracellular switches and master regulators of GSL expression are. Knowledge of cytokineinduced signaling cascades, whether or not in the context of differentiation or activation, is important to understand GSL regulation and may provide opportunities for the design of intervention strategies. Up to now, regulation of GSL expression on immune cells has mainly been studied by addition of key cytokines such as interleukins, interferon- $\alpha$ (IFN- $\alpha)$, and tumor necrosis factor- $\alpha$ (TNF- $\alpha$ ) (Figure 3).

IL-4 and especially IL-6 induce expression of Fo GSLs at early stages of mouse BMDM culture, but neither could promote further Fo GSL expression once the intrinsic maximum of these cells had been reached $(104,105,133)$. The mechanism of these IL- 4 and IL- 6 regulated differences in GSL composition is still unclear. One option may be that these interleukins coordinate GSL synthesis through modulation of the nucleotide sugar metabolism. IL-4 and IL-13 have the ability to upregulate the levels of UDP-GlcNAc which is a key nucleotide sugar donor for GSL synthesis. The increased activity of corresponding transcriptional enzymes involved in the production of these intermediates (e.g., Enpp1, Pgm1) was reported for IL-4 activated M2 polarized macrophages as well, and was not observed in IFN- $\gamma$ and toll-like receptor-induced M1 macrophage polarization (134). An alternative mechanism of GSL regulation was provided by overexpression of IL-3 in mouse NFS6017 cells, which leads to the specific synthesis of GD1a $(114,123,135)$. This change in GSL expression is caused by increased GM3 synthase levels, since other GTs involved in GD1a synthesis were not significantly altered by IL-3 expression. Thus, regulation of GT expression can result in a shift in the GSL repertoire, in this case from $o$-series to $a$ - and $o$-series gangliosides (Figure 3). IFN- $\alpha$ induces more significant alterations in GSL biosynthesis in mouse B cells compared to other cytokines, including IL-6 and IL-10. In particular, GlcCer, LacCer, and Gb3 are significantly upregulated (65). These changes were attributed to the enhanced expression of UGCG and A4GALT. IFN- $\alpha$ also represses $\alpha$-galactosidase that catalyzes the degradation of Gb3 further contributing to Gb3 accumulation (65). The effect of TNF- $\alpha$ on GSL expression has been described in several studies. TNF- $\alpha$ binding to its cognate receptor TNFR1 has been reported to enhance ceramide production by upregulating the acidic sphingomyelinase, a ceramide generating enzyme (136, 137). Furthermore, TNF- $\alpha$ increased Gb3, GM2, and GM3 through increased transcription of their specific synthases (134, 138-140). TNF- $\alpha$ also mediated upregulation of GM2 in tumor cells and accelerated tumor-induced $\mathrm{T}$ cell apoptosis and immune dysfunction. Furthermore, TNF- $\alpha$ was found to activate sialidases through p38 mitogen-activated protein kinase in lipopolysaccharide(LPS)-stimulated human monocytes, suggesting that TNF- $\alpha$-induced p38 activation may regulate GSL expression (141).

\section{Regulation of GSL Expression by Other External Signals}

Not only cytokines but also other factors have been observed to alter GSL expression. The presence of high-affinity Fc\&RI is suggested to contribute to the expression of gangliosides. FceRI positive HMC-1 cells expressed 3-fold higher levels of GM3 compared to the Fc $\varepsilon$ RI negative counterparts. Furthermore, detectable amounts of the gangliosides GM2, GM1, and GD1a were found only in the Fc\&RI positive HMC-1 cells, with a corresponding increase of mRNA for GalNTs in the presence of the FceRI. These findings suggest that FceRI signaling enhances ganglioside production (25). Similarly, TCR stimulation on naïve $\mathrm{CD}^{+} \mathrm{T}$ cells upregulated GM1 expression, which is crucial for responding to self-MHC ligands and IL-2 (117). GM1 levels declined after cell transfer to MHC-I Iow $\left(\mathrm{Tap}^{-/-}\right)$ mice, indicating that maintenance of GM1 expression required continuous TCR-MHC-I interaction. By contrast, CD4 ${ }^{+}$T cells 


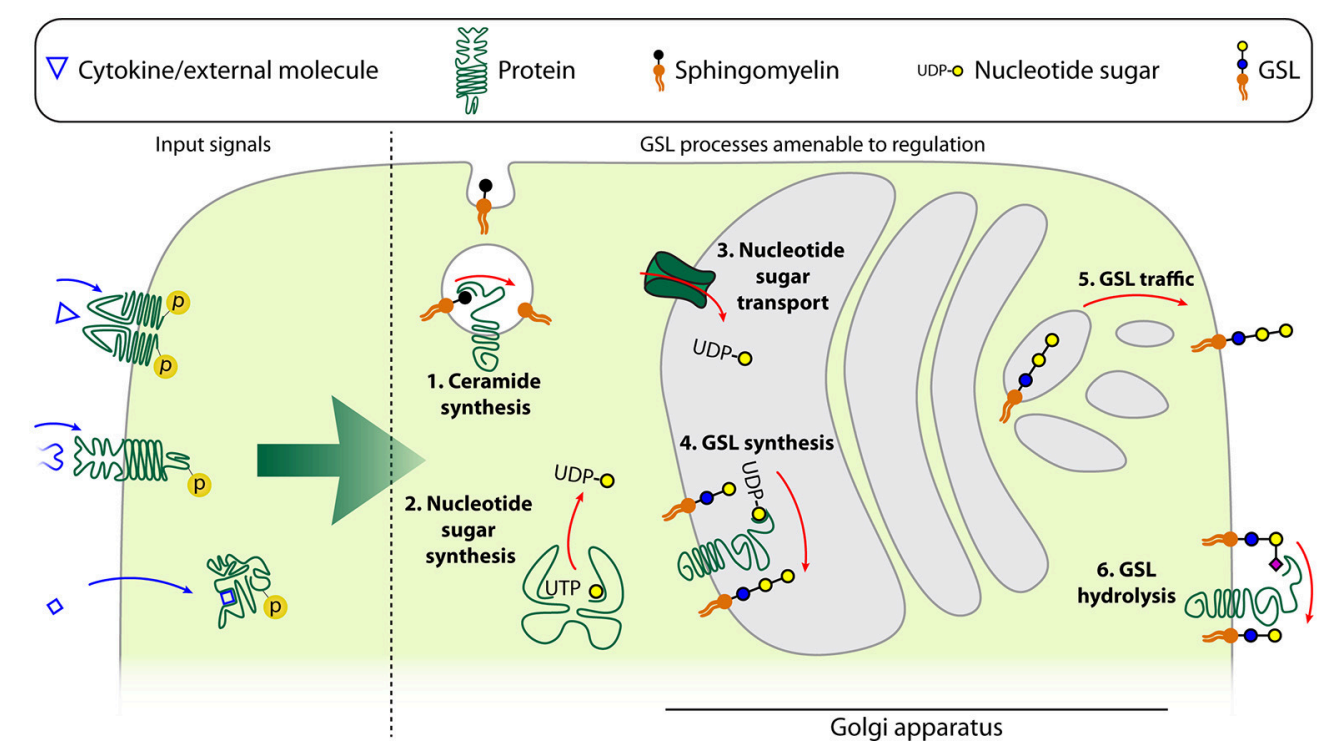

FIGURE 3 | Schematic model of the different levels of GSL regulation. Input signals described to be able to affect the GSL repertoire of a cell are either cytokines, other ligands with membrane-bound receptors or ligands with intracellular receptors. These affect the GSL repertoire by changing the expression or activity of ceramide synthases such as acidic sphingomyelinase (1), nucleotide sugar synthases in the cytoplasm (2), nucleotide sugar transporters which transport the nucleotide sugars into the Golgi apparatus (3), glycosyltransferases (4), trafficking of the GSLs from the Golgi apparatus to the plasma membrane (5), or glycosidases (6).

expressed low amounts of GM1 and were unresponsive to IL-2 (117). In addition, both NEU1 and NEU3 mRNAs were significantly induced in human T cells by TCR stimulation, potentially leading to a decrease of sialylated GSLs (Figure 3) (120). Wang et al. further revealed that NEU3 is expressed as a major isoform in activated cells. Transcription of NEU expression in T cells is enhanced by FLI1, whose activity is potentially driven by TCR stimulation. Genetic reduction of FLI1 expression in T cells thus decreased NEU1 and NEU3 levels but also overall GSL expression. However, the mechanism by which FLI1 influences GSL expression is not clear yet (118). GSL levels on $\mathrm{CD} 4^{+} \mathrm{T}$ cells can also be boosted by stimulation with synthetic liver X receptor (LXR), which signals through the nuclear receptor LXR $\beta$. Stimulation of LXR is known to directly control expression of NPC1 and NPC2 proteins, which regulate cellular GSL transport and recycling (Figure 3). Therefore, an elevated LacCer, Gb3, and GM1 expression in $\mathrm{CD} 4^{+} \mathrm{T}$ cells with highly expressed LXR $\beta$ was achieved, which associated with accelerated and sustained GSL internalization and recycling dynamics. Interestingly, this enhanced GSL expression is not correlated with changes in synthase expression but rather associated with the intracellular accumulation and accelerated trafficking of GSLs (67). Yet another GSL modulating stimulus is heparin, which modulates the expression of GSLs in lymphocytes activated by IL-2. Heparin treatment induces downregulation of certain GSLs, including GM1, GD1a, LacCer, asialo GM1, and asialo GM2, whereas globoside and Fo antigen levels are elevated. These changes were attributed to heparin-mediated inhibition of $\alpha 2-3$ sialyltransferase and a $\beta 1$ 3 galactosyltransferase, possibly via heparin-binding domains (142).

\section{Considerations on Regulation of GSL Expression}

GSL expression is highly controlled at multiple levels, such as the availability of nucleotide sugars and glycosyltransferases (Figure 3). Our understanding of how the GSL synthesis pathway is regulated in specific immune cells needs be improved. The fact that the physiological role of most immune cells is known will then provide opportunities to unravel molecular functions of specific GSLs in these cells. In addition, various laboratories have identified environmental factors that manipulate the GSL repertoire by seizing on components of the GSL synthesis pathway. The limited number of papers describing such regulation of GSL synthesis clearly indicates that this is an underexposed field. Moreover, the available data seems to be biased toward the more well-known soluble proteins. We expect many more GSL regulatory factors to exist that are not yet linked to GSL synthesis. The identification of such GSL modulatory processes may have implications for GSL manipulation in research and potentially even in clinical contexts.

\section{FUNCTIONS OF GSLS ON IMMUNE CELLS Organization of Membrane Microdomains}

GSLs are mainly known for their role in membrane organization which is a dynamic process, especially during activation and differentiation of immune cells. In resting immune cells, GEMs (Figure 4A) are suggested to be unstable and small in size. Immune cell activation triggers a change in localization of receptors and signal transducers, in many cases to or from GEMs, which is required to bring receptors and signal 


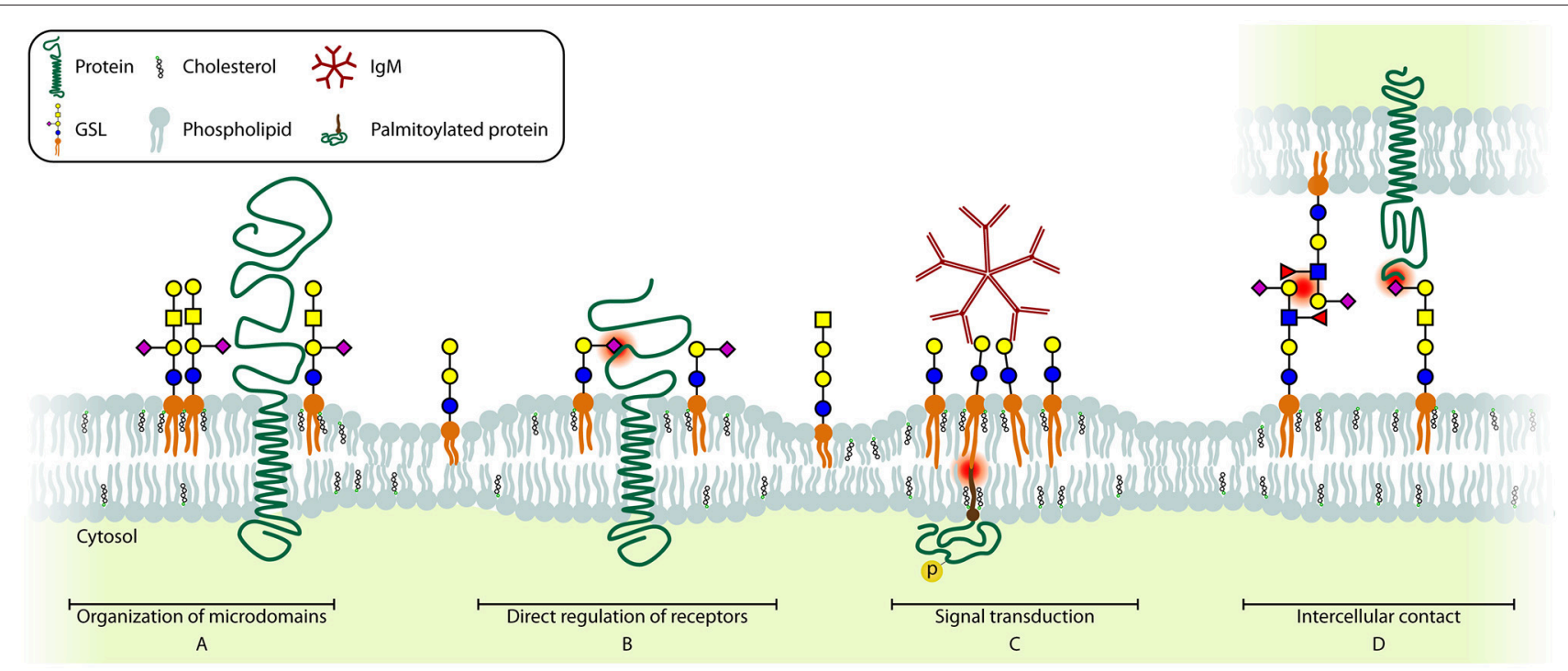

FIGURE 4 | Schematic model of the different GSL functions. Essential glycan-glycan, protein-glycan, and lipid interactions are highlighted (red dot). (A) GSLs are involved in including and (not shown) excluding proteins from microdomains. (B) Several receptors can be directly regulated by GSLs present in the cell membrane. (C) Crosslinking of several GSLs can induce signaling across the membrane. (D) GSLs can interact with glycans (CCl, left) or with proteins (PCl, right) on other cells, contributing to cell-cell recognition and adhesion.

transducers in close proximity to enable signaling $(143,144)$. The best described example in $\mathrm{T}$ cells is the activationinduced recruitment of the TCR/CD3 complex to GM1 GEMs together with downstream signaling molecules Lck, SLP-76, and palmitoylated LAT. At the same time, the phosphatase CD45 is excluded from GEMs, further increasing the sensitivity of the TCR (145-151). Additionally, the IL2R $\beta$ is recruited to GM1 GEMs upon stimulation, which is required for its signaling (117). Interestingly, when GM1 GEMs were crosslinked by CTB and anti-CTB antibodies, TCR-like signaling was observed, suggesting that multiple signaling molecules are brought together by crosslinking multiple GM1 GEMs, which indicates a diversity in GM1 GEMs content in different plasma membrane patches (148). General disruption of GEMs in T cells results in a lack of receptor recruitment and exclusion from the immunological synapse, which causes desensitization for ligands and greatly reduced or absent $\mathrm{T}$ cell activation. Interestingly, no difference in $\mathrm{T}$ cell development has been observed in mice with a $\mathrm{T}$ cell specific deletion of UGCG. However, no functional characterization was performed on these $\mathrm{T}$ cells other than PMA/ionomycin stimulation, which bypasses signaling from the membrane. In contrast, the development of invariant NKT cells that recognize CD1d-restricted antigens was found to be impaired in these mice (152).

Once B cells encounter an antigen, caveolin-1 recruits the IgM BCR to GM1 GEMs (153-155). The lack of caveolin-1 results in impaired BCR signaling which results in decreased receptor editing and ultimately autoimmune B cells (155). Also MHC-II molecules on B cells require clustering to GM1 GEMs in order to efficiently trigger $\mathrm{CD} 4^{+} \mathrm{T}$ cell help at low ligand densities $(156,157)$. Additionally, B cells in B3GNT5 ${ }^{-/-}$mice, which lack (neo)lacto-series GSLs, display alterations in the structure of GM1 GEMs containing BCR, CD19, and Lyn, resulting in increased antigen sensitivity. Consequently these B cells are also more prone to generate autoreactive antibodies (158).

Thus, in both T and B cells, GM1 is part of GEMs that have a crucial role during activation of these cells. The fact that other GSLs expressed by these cells (see section Biosynthesis and Expression of GSLs in Naïve and Differentiated Immune Cells) have not been investigated in this context is likely due to a lack of detection and visualization methods. Importantly, the plasma membrane may contain a large diversity of domains or GEMs with a slightly different (glycosphingo)lipid and protein content as proposed in the revised Fluid-Mosaic Membrane Model (144). Each domain with physically distinct properties may have a specific function, also in immune cells (144). Techniques to visualize these nanometer-domains without introducing artifacts are still scarce. While detection of GM1 by cholera toxin CTB is a broadly accepted method, probes that are considered specific for other GSLs are less well-established, introducing a strong bias toward GM1 GEMs investigations. Therefore, the function of other GSL containing membrane domains and their role in membrane organization is still largely unclear.

\section{Direct Regulation of Immune Receptors}

A second function of GSLs is their direct regulation of surface protein function (Figure 4B). One of the best-described interactions between GSLs and proteins is the interaction between insulin receptor and GM3. Insulin receptor binds the acidic GM3 through a basic lysine residue (K944) resulting in inhibition of insulin-induced signaling. Thus, upregulation of GM3, for example after TNF- $\alpha$ stimulation, results in insulin resistance $(139,159)$. Similarly, autophosphorylation of the Epidermal Growth Factor Receptor (EGFR) in the absence of 
EGF is prevented by binding of GM3 via a lysine residue (K642) (160).

On immune cells, only few GSL-receptor interactions have been reported, often with limited molecular details. Upon activation of the Toll-Like Receptor 4-Myeloid Differentiation factor 2 (TLR4-MD2) with LPS, Gb4 synthesis is upregulated in mouse endothelial cells. Gb4 can bind the TLR4-MD2 complex to desensitize the LPS-activated signaling pathway thus representing a negative feedback loop (161). Since Gb4 and the TLR4-MD2 complex are also expressed on early human myeloid cells and mature monocytes (23), one may speculate that a similar regulation applies to human immune cells. Interestingly, GlcCer on the membrane of macrophages is essential for efficient LPSinduced TLR4-MD2 signaling since inhibition of GSL-synthesis prior to incubation with LPS significantly reduced cytokine release. In silico simulations to explain these observations suggest that GlcCer induces a conformational change of TLR4 thereby enhancing the interaction between TLR4 and the intracellular signaling molecule Mal (52).

In T cells, CD4 interacts with GM1, and additional GM1 incorporation into the membrane results in masking of some CD4 epitopes for antibodies and a subsequent internalization of CD4 molecules, with the underlying mechanisms being unknown. Additionally, GM1 binds PI3K whereas GM3 binds LCK. In order to get successful T cell activation LFA-1 links CD4 and PI3K to LCK by binding both GM1 and GM3 $(162,163)$.

GSLs are also important for strengthening protein-protein interactions in tetraspanin-rich microdomains. An example of the stabilizing function of GSLs is the enhanced binding of the tetraspanins CD9 and CD82 to integrins in the presence of GM3 and GM1, respectively $(164,165)$. Thus, GSLs may impact integrin mediated immune cell migration (166). Additionally, loss of functional tetraspanin-rich microdomains results in uncontrolled receptor activity, such as uncontrolled activation of the MET receptor tyrosine kinase and decreased EGFR sensitivity $(165,167)$. CD82 expression also correlates with increased GM1 and GD1a levels on the cell surface, suggesting an interplay between GSLs and tetraspanin expression either by increasing GSL synthesis or by extending the half-life of GSLs on the plasma membrane (168).

Since CD19 shares amino acid sequences with the Gb3 binding domain of the E. coli produced verotoxin, the Daudi B cell line was modified to lack Gb3, which impaired CD19 surface expression. However, the mechanism was not elucidated and since only a subpopulation of germinal center B cells express Gb3 while CD19 is expressed on all B cells, the finding may be an artifact of the cell system that was used $(112,169)$. Using the same approach MHC-II was identified as another protein that contained a possible Gb3 binding domain, which could be relevant in for example germinal center reactions of $\mathrm{B}$ cells, but also for other professional antigen presenting cells such as macrophages and DCs which also express considerable amounts of $\mathrm{Gb} 3$ (see section Biosynthesis and Expression of GSLs in Naïve and Differentiated Immune Cells). Unfortunately, no binding data are available for the MHC-II-Gb3 interaction, thus the functionality of these domains is still unclear (170).
Activation of Notch by its ligand Delta-like 1 (Dll1) is dependent on binding of Dll1 to LacCer. Either mutating the LacCer binding site of Dll1 or inhibiting GSL synthesis impairs the capacity of Dll1 to activate Notch (171). This may be relevant during $\mathrm{T}$ cell development, where Notch signaling plays a major role (172).

The internalization route of Fas receptor upon ligation with Fas ligand is determined by its interaction with LacCer or Gb3 which results in an endocytotic pathway leading to apoptosis, while the GSL-independent route induces proliferation and differentiation (173). Expression of Gb3 by B cells (112) during the germinal center reaction may support the apoptotic events required for $\mathrm{B}$ cell selection.

Besides direct interactions between GSLs and proteins described above, there are also reports on interactions between $N$-glycans and GSLs. The ganglioside GT1b can interact with mannose residues on the $N$-glycan of the $\alpha 5$-integrin, thereby inhibiting integrin-fibronectin interaction (174). Regulation of integrin activity by GT1b may play a role in T cell development, where $\alpha 5 \beta 1$ integrin signaling plays a role in $\mathrm{T}$ cell selection $(175,176)$.

\section{GSLs as Signal Transducers}

Direct interaction of GSLs with surface receptors may thus have profound impact on signaling events. But GSLs can also transduce signals across the membrane themselves (Figure 4C). Crosslinking GSLs by multivalent binders such as bacterial toxins CTB and Shiga Toxin (ST), or alternatively IgM antibodies, has been found to increase intracellular calcium levels that in turn activate Syk $(177,178)$. This influx of calcium ions upon GM1 crosslinking on the cell surface may be through modulation of L-type calcium channels. Additionally some GSLs regulate intracellular calcium levels by affecting the function of the calcium-dependent messenger protein calmodulin (179, 180). The result of Gb3 crosslinking using ST or anti-Gb3 $\mathrm{mAbs}$ in germinal center B cells induces recruitment of Lyn/Syk and the BCR and subsequent internalization of the complex leading to apoptosis (181). Interestingly, the pathways leading to apoptosis differ between ST or anti-Gb3 mediated crosslinking of Gb3 (182-185). Similarly, crosslinking of $\mathrm{GM}^{+}$patches in $\mathrm{T}$ cells using crosslinked CTB induces LCK-dependent TCR-like signaling (148). Interestingly, crosslinking of $\mathrm{GM}^{+}$patches by the $E$. coli heat-labile enterotoxin $\mathrm{B}$ induces apoptosis in $\mathrm{CD} 8^{+}$ $\mathrm{T}$ cells specifically (186). However, there are some doubts on the specificity of these two toxins, which may explain differences in results obtained.

In neutrophils, the kinase Lyn is associated with LacCer enriched microdomains. Crosslinking of these microdomains by anti-LacCer IgM antibodies induces Lyn activation and ultimately leads to superoxide production (39). This signal transduction from LacCer molecules to the palmitoylated form of Lyn is dependent on the length of the fatty acid chain of the GSLs; Lyn is only activated when the fatty acid chain contains 24 carbon atoms and not with shorter fatty acids of 22 or 16 carbon atoms, suggesting that the signal is transmitted within the lipid bilayer relying on specific interactions of the lipid tails $(187,188)$. Although the length of the fatty acid chain also 
influences the general membrane organization and association with proteins which is not addressed yet, a similar association has been described for Lyn and c-Src with photoactivatable GD1b in rat cerebral granule cells (189).

\section{Intercellular GSL Functions}

There are two mechanisms by which cells interact with GSLs on other cells; via protein-carbohydrate interaction (PCI), and via carbohydrate-carbohydrate interaction (CCI) (Figure 4D). Proteins known to engage in PCI are called lectins, and human lectins may be grouped into three major classes; (1) selectins, that typically bind glycans that are both sialylated and fucosylated, (2) siglecs, which bind sialylated glycans, and (3) galectins, that bind glycans with a terminal galactose. The function of these lectins differ per cell type, with selectins being the major mediators of cell-cell adhesion, particularly between activated endothelial cells and leukocytes. Siglecs specifically interact with sialic acids and are mainly found on hematopoietic cells. Galectins, on the other hand, often bind terminal galactoses and can modulate cell growth, apoptosis, differentiation, and migration (190).

CD83 is an I-type lectin adhesion receptor that is mainly expressed by mature dendritic cells but is also found on activated $\mathrm{B}$ and T cells. CD83 interacts with sialic acids on monocytes and activated $\mathrm{CD}^{+} \mathrm{T}$ cells and is required for efficient $\mathrm{T}$ cell activation (191). Although the ligand for CD83 was identified as a glycan carried by a glycoprotein on the T cell line HPB-ALL, the authors do not rule out the possibility of ligands carried by GSLs (192).

The sialic acid binding receptor on B cells, CD22 or siglec2 , recognizes $\alpha 2,6$-linked sialic acids that are predominantly expressed in eukaryotes. When the $\mathrm{B}$ cell is in an inactive state, CD22 is associated with sialic acids on the B cell surface. However, once the B cell becomes activated, the CD22 is unmasked, and can engage in trans-interactions with sialic acids on other cells which induces inhibitory signaling $(193,194)$. NK cell activation may be controlled by siglec-7 in a similar manner $(195,196)$. The current hypothesis is that these interactions prevent activation of auto-reactive B and NK cells (197).

Cell-cell interaction in the immune system is critical at sites of inflammation. Inflammation-mediated activation of endothelial cells upregulates selectins like E-selectin in order to recruit immune cells (198). The ligand for E-selectin on neutrophils is a GSL that contains poly-LacNAc repeats with at least two fucose residues and a terminal sialic acid, but E-selectin may also bind GSLs and glycoproteins containing the sialyl-Le ${ }^{\mathrm{x}}$ motif (Figure 1B). This interaction is of low affinity and induces typical neutrophil rolling on the endothelium, which is required for transmigration afterwards (199).

CCIs are studied to a lesser extent compared to PCIs. They are involved in early embryogenesis, where the compaction of the embryo is dependent on $\mathrm{Le}^{\mathrm{x}}$ structures [for review, see (200)]. Additional reports on CCI describe the interaction between GM3 or Gb4 and asialo GM2 (201). Although a single CCI is generally of very low binding affinity, the carbohydrates may be so prevalent that they may act as a zipper to mediate strong cell-cell adhesion, comparable to CPI or even protein-protein interaction $(200,202)$.
Although still poorly understood, B cells communicate by forming nanotubes in certain differentiation stages which correlate with expression of GM1 and GM3. The formation of these nanotubes was inhibited by methyl- $\beta$-cyclodextrin induced cholesterol depletion, which destroys the integrity of GEMs. Furthermore, only cells with high levels of raftophilic sphingomyelin and phosphatidylcholine generated nanotubes. Thus, the formation of these nanotubes depends on functional GEMs which is possibly related to their GSL contents (203).

\section{Considerations on Molecular Functions of GSLs}

GSLs clearly play a role in immunological processes involving cell-cell recognition, adhesion, and communication. However, most of the studies merely provide evidence that certain GSLs are required or sufficient for a particular process, while the exact molecular role of such GSLs remains to be identified for most of these processes. Such mechanistic studies are sparse for a reason, because molecular evidence is often hard to obtain with the current tools. Furthermore, the studies are still limited to a few specific GSLs and do not cover all GSL subtypes. For example, (neo)lacto-series GSLs have largely been neglected in investigations. The relatively recent generation of B3GNT5 knockout cancer cell lines and mice are important initiatives to extend our knowledge on the physiological role of these elusive GSLs $(158,204)$. Thus, many aspects of GSL functions are still unclear and require further in depth investigations.

\section{RELATIONS BETWEEN GSLS AND IMMUNITY IN DISEASE}

Congenital diseases, infections, and cancer showcase aberrant GSL expression, which provides opportunities to gain new insights in (dys)regulation and functions of GSLs. Such knowledge may provide new targets for therapeutic intervention, of which the most recent developments are described in section Targeting GSLs: Opportunities for Treatment.

\section{Gaucher Disease}

Patients with Gaucher disease lack the enzyme glucosylceramidase, which is required for the breakdown of GlcCer. Besides neuronal abnormalities this disease is characterized by the presence of large "Gaucher cells" which are macrophages with accumulated GlcCer in lysosomes that concentrate in the spleen and bone marrow. The formation of splenic Gaucher cells is enhanced by rapid splenic clearance of defective red blood cells by macrophages (205). Patients suffering from Gaucher disease are treated either with enzyme replacement therapy or with substrate reduction therapy which consists of the administration of UGCG inhibitors such as $N$-butyl-deoxynojirimycin (Miglustat) $(205,206)$.

\section{Infection}

Various pathogens dysregulate the cellular GSL metabolism, leading to different compositions of the cell surface GSL repertoire. The $\mathrm{p} 40^{\mathrm{tax}}$ protein encoded by the human $\mathrm{T}$ cell lymphotropic virus, can induce GD2 expression by upregulating 
B4GALNT1, which is normally not expressed in T cells (207). Similarly, it was shown that cytomegalovirus (CMV) induces enhanced synthesis of GSLs, of which specifically (neo)lactoseries remain expressed long after initial infection $(208,209)$. Additionally, herpes simplex virus alters gene expression of a variety of GTs. The significance of these changes still need to be addressed since the authors could not detect major differences in the profile or total amount of GSLs after infection (210). A potential reason for such dysregulation may be to escape from detection and elimination by the immune system.

Several infectious pathogens and toxins are well-known to use GSLs as cellular entry receptor. Next to CD4, HIV can infect cells through Gb3 and possibly also GM3. Shigella bacteria target only activated $\mathrm{CD} 4^{+} \mathrm{T}$ cells likely through their GM1 and GM3 expression which was inhibited by exogenously added LPS, suggesting a direct interaction between LPS and the gangliosides (211). This would imply that also other gram-negative bacteria may enter host cells through binding of their gangliosides (212).

A variety of bacterial toxins have been described to target GSLs using their binding subunit (B subunit) in order to bring their enzymatically active subunit (A subunit) inside the cell. In 1973, one of the best known toxins, cholera toxin, was described to bind GM1 (213). Although generally used as a marker for GM1, CTB can bind asialo GM1, Fuc-GM1, GD1a, GD1b, GT1b, GM2, GM3, and also to $\mathrm{Le}^{\mathrm{x}}$ on glycoproteins although usually with lower affinity. Similarly, it was long thought that enterotoxin B was GM1-specific, until it was shown to cross-react with asialo GM1, GD1b, LacCer, and several galactoproteins (214-216). The B subunit of shiga toxins ( $\mathrm{STb}$ ) and verotoxins associate with Gb3, although all bind Gb3 in a slightly different way (217). Since STb binding to Gb3 induces endocytosis and $\mathrm{Gb} 3$ is present on DCs, some research has been devoted to exploiting STb for tumor vaccination (218). However, STb elicited a cytotoxic effect through binding of an $\mathrm{N}$-glycan on HeLa cells, suggesting this strategy may have serious side-effects when applied in humans (219). The toxic effects of tetanus toxin and botulinum toxin were greatly reduced in B4GALNT1 (GD2-synthase) deficient mice, suggesting their natural ligands are at least partly complex gangliosides (220). Confirming these findings, type A botulinum progenitor toxin bound asialo GM1, nLc4 and $N$-glycans containing a terminal GalB1-4GlcNAc (221). Despite these health risks, the physiological function of specific GSL structures was apparently too critical to be efficiently counterselected against during human evolution. Although GSLs are essential during embryonic development, this may also partially be due to the versatile roles of GSLs in immunity.

Finally, several bacteria have the capacity to bind GSLs but it is currently unclear what the pathophysiological reason is for this phenomenon. Helicobacter pylori, a microaerophilic organism that can cause severe gastritis, binds to sialic acid-containing GSLs on neutrophils, thereby activating the neutrophil to produce reactive oxygen species $(222,223)$. Interestingly, neutrophils can phagocytose the bacteria but it seems able to escape the immune cell and cope with the immune response $(222,224)$. Neisseria bacteria, mostly known for their genera meningitides and gonorrhoeae, are also capable of binding GSLs, although it differs per strain which GSLs they adhere to.
N. subflava binds sialylated GSLs on erythrocytes by its adhesin Sial (225) whereas N. gonorrhoeae has an adhesin binding LacCer and asialo GM1 (226). N. meningitides binds a wider array of GSLs; LacCer, asialo GM2, asialo GM1, nLc4 but also sialylated nLc6 (227). Additionally, phagocytosis of N. meningitidis by neutrophils appears to depend on their expression of (neo)lactoseries GSLs since it is blocked by the LacNAc-Gal-binding antibody 1B2 (228)

The importance of GEMs for the phagocytosis of yeast, such as Cryptococcus neoformans, by macrophages has been welldefined since disruption of GEMs using methyl- $\beta$-cyclodextrin decreases internalization (229). However, Jimenez-Lucho et al. have shown specific binding of C. neoformans, Candidia albicans, and other fungi to LacCer, suggesting indeed a role of these GSLs as adhesion receptors for yeast (230). This was confirmed by the identification of an interaction between the bacterial and fungal cell wall polysaccharide $\beta$-glucan and LacCer on neutrophils, which triggers superoxide production and $\mathrm{CD} 11 \mathrm{~b} / \mathrm{CD} 18$-mediated phagocytosis of the pathogen (231). These examples indicate potential pathways for different pathogens to be captured by phagocytes, which play an important role in the antimicrobial defense. Moreover, the specific GSL repertoire of neutrophils may allow for improved detection of bacteria, or other pathogens, and possibly contribute to fight infections.

\section{Cancer}

Tumors often express high levels of GSLs, which interferes with the killing capacity of the immune system. These high levels of GSLs result, either via an active or passive process, in high concentrations of free GSLs in the tumor microenvironment. For some tumors, such as neuroblastoma, the plasma concentration of tumor-derived GSLs was 50 times elevated as compared to the same patients after treatment or healthy controls (232, 233). Multiple modes of action have been described for the immunosuppressive characteristics of free GSLs.

A portion of $\mathrm{T}$ cells isolated from renal cell carcinoma were found to be GM2 positive, while lacking the machinery for GM2 synthesis, suggesting the T cells adopted the GM2 from the tumor microenvironment. These $\mathrm{T}$ cells exhibited increased rates of apoptosis compared to their GM2 negative counterparts (234). In addition, ex-vivo $\mathrm{T}$ cells treated with renal cell carcinoma-derived gangliosides also show a decrease in NFkB signaling (235). T cells incubated with exogenous GD1a lose cytotoxicity since polarization and exocytosis of lytic granules is inhibited, we speculate this may also be due to incorporation of soluble gangliosides in the plasma membrane, disrupting the organization required for proper $\mathrm{T}$ cell function (236). Additionally, $\mathrm{CD} 4^{+} \mathrm{T}$ cells cultured in the presence of GT1b led to a shift from an IFN- $\gamma$ secreting type-1 phenotype to an IL-4 producing type-2 phenotype (237). Finally, various individual brain-derived gangliosides inhibit $\mathrm{T}$ cell proliferation possibly through competing for the IL-2 binding place on the IL-2 receptor or via direct binding to cytokines such as IL-4 and IL-15 (238-241).

Similar to T cells, also DC differentiation and maturation is inhibited by gangliosides through inhibition of NFKB signaling 
(242, 243). Besides, brain-derived gangliosides inhibit MHC-II antigen presentation by monocytes (244). GM2 and GM3 shed by melanomas were potent inhibitors of Fc receptor expression on monocytes and macrophages whereas GM1 and GD3 inhibited IL-1 $\beta$ production (245). Similarly, GM2 and GM3 were potent inhibitors of NK cell activity. Since GM2 showed reduced effector-target cell binding and GM3 did not, they are likely to act through different mechanisms (246). IL-3 dependent proliferation of BMMCs was inhibited by GM3, but in contrast to earlier proposed mechanisms, the authors excluded direct GM3IL-3 interaction. However, it remains unknown whether the mechanism may be through competition with IL-3 for the IL-3 receptor (247). In summary, high concentrations of gangliosides shed by tumors lead to a downregulation of the cellular immune response.

Conversely, microglia downregulate TLR4 while upregulating TLR2 in the presence of free gangliosides, which thus contribute to inflammatory conditions in the brain (248). However, the mechanism by which gangliosides affect the microglial phenotype and whether this actually contributes to an inflammatory state in the brain has yet to be established.

\section{TARGETING GSLS: OPPORTUNITIES FOR TREATMENT}

\section{Targeting of GSLs Using Antibodies/CAR T Cells}

Since tumors often upregulate GSL expression, as discussed in the previous chapter, the 75 cancer antigen priorities of the National Cancer Institute at Rockville (USA) lists 4 different GSLs (249). The first one on the list is GD2, for which an antibody (dituximab beta; ch14.18/CHO) is currently being tested in phase III trials for patients with neuroblastoma (trial NCT01704716). Additionally, chimeric antigen receptors (CARs) have been designed and overexpressed in $\mathrm{T}$ cells to target GD2 overexpressing neuroblastoma (250-252). Next, an antiGD3 antibody-drug conjugate (PF-06688992) is in a Phase I clinical trial for patients with stage III or IV melanoma (trial NCT03159117). Also for this GSL-target, CARs have been developed (253). Fucosyl-GM1 is being targeted by the antibody BMS-986012 that is currently tested in the preclinical phase with the goal to treat patients with small-cell lung carcinoma (254). The last GSLs on the list is GM3 for which an antibody is undergoing preclinical investigation by Morphotek.

Yet another option is to vaccinate with GSLs or structures that bear GSL antigens in order to induce an antibody response toward the GSLs overexpressed by a patient's tumor. The disadvantage, however, is that vaccinations with carbohydrates require (a lot of) purified carbohydrates and often result in $\mathrm{CD}^{+} \mathrm{T}$ cell independent low affinity IgM responses without long-lived B cell memory (255). To overcome these challenges, either purified carbohydrates or synthetic polymers harboring the epitope can be fused to carrier proteins (e.g., keyhole limpet hemocyanin or tetanus toxoid) that are able to induce $\mathrm{CD} 4^{+}$ $\mathrm{T}$ cell activation. Since conjugation of carbohydrate epitopes to proteins is hard to control, fully synthetic vaccines are being developed (256).

\section{Inhibition of GSL Synthesis to Active Immune Cells}

In 2003 and 2014 the UGCG inhibitors Miglustat [N-butyl 1-deoxynojirimycin (NBDNJ)] and Eliglustat, respectively, received FDA approval for treatment of Gaucher disease in order to prevent accumulation of GlcCer in these patients. Until 1994 , NBDNJ was described to inhibit $\alpha$-glucosidases in the $\mathrm{N}$-glycosylation pathway. In vitro work on purified proteins shows that the $\mathrm{IC}_{50}$ for NBDNJ was $0.57 \mu \mathrm{M}$ for $\alpha$-glucosidase I and $20.4 \mu \mathrm{M}$ for UGCG. However, due to localization of UGCG on the cytoplasmic side and $\alpha$-glucosidase I on the luminal side of the ER, a 10-fold lower concentration NBDNJ is required to inhibit UGCG compared to $\alpha$-glucosidase I in intact cells (257-259). For long it has been hypothesized that inhibitors of GSL synthesis like NBDNJ could also be beneficial for other diseases including cancer (260).

In several mouse models it has been shown that inhibition of GSL synthesis decreases tumor load or even cured the mice (261). Moreover, in a multiple myeloma mouse model, inhibition of GSL synthesis decreased osteoclast activation and thereby the osteolytic lesions that are often present in multiple myeloma patients (262). Since it is even suggested that aberrant GSL synthesis by tumors cause drug-resistance $(263,264)$, inhibiting GSL synthesis would be great for a combination therapy. Apart from drug-resistance, high expression of GSLs by tumors also negatively affects $\mathrm{T}$ cell and $\mathrm{DC}$ function, so GSL synthesis inhibition could also be beneficial for cancer immunotherapies.

However, in a Phase I trial where NBDNJ was administered to HIV patients it was found that some patients developed borderline or transient leuko- or neutropenia that was unrelated to dosage (265). In addition, GSL inhibitors may have a negative effect on lymphocyte development and maturation in vivo (266), In the case of anti-tumor treatment, however, the patient population would only have a temporary inhibition of GSL synthesis and a functional immune system. Additionally, studies in patients suffering from Gaucher disease do not mention any immune-related side-effect of NB-DNJ (267-269). In this review, we discussed several functions of the immune system that rely on GSLs, therefore it is likely that some functions may be impaired by GSL synthesis inhibitors and their off-label use should be well-substantiated.

\section{CONCLUDING REMARKS}

It is clear by now that GSLs are important constituents of a functional immune system. GSLs play versatile roles in physiology and pathophysiology. The knowledge on these roles is largely skewed by the limitations of the tools available. Still, investigators have discovered on a molecular level that GSLs are essential for the recruitment of (immune-related) proteins to specific membrane microdomains and that GSLs 
can directly interact with surface receptors. Interactions directly with molecules on other cell types further shape the multifaceted function of GSLs in immunity. We believe that these GSL functions are closely interconnected to control immune cell function through dynamic regulation of GSL composition. As a consequence, various pathologies are highly related to specific GSL repertoires. We therefore also provided a brief summary of the therapeutic opportunities of GSL synthesis dysregulation that are currently being evaluated. New mechanistic insights in the (immunological) functions of GSLs in health and disease will allow to expand the described options and applications. Available state-of-the-art technologies will be of great help to take the field a great leap forward. Specifically, a validated gRNA library to target all known human GTs by CRISPR/Cas9 has been recently constructed (270). Difficulties of introducing the CRISPR/Cas9 machinery into primary immune cells, such as B and T cells, have also been overcome by electroporation protocols and the usage of recombinant gRNA-loaded Cas9 (271, 272). Furthermore, the development and combination of high-sensitive analytical platforms based on mass spectrometry have boosted the detection of less common GSL-species. And the current throughput and analysis efficiency allows for comprehensive profiling, quantification, and structural characterization of GSLs extracted from tissues and cells (48, 273-275). All these advancements

\section{REFERENCES}

1. Haslam SM, Julien S, Burchell JM, Monk CR, Ceroni A, Garden OA, et al. Characterizing the glycome of the mammalian immune system. Immunol Cell Biol. (2008) 86:564-73. doi: 10.1038/icb.2008.54

2. D'Angelo G, Capasso S, Sticco L, Russo D. Glycosphingolipids: synthesis and functions. FEBS J. (2013) 280:6338-53. doi: 10.1111/febs.12559

3. Nakayama H, Ogawa H, Takamori K, Iwabuchi K. GSL-enriched membrane microdomains in innate immune responses. Arch Immunol Ther Exp. (2013) 61:217-28. doi: 10.1007/s00005-013-0221-6

4. Sonnino S, Prinetti A. Gangliosides: Methods and Protocols. New York, NY: Humana Press (2018). doi: 10.1007/978-1-4939-8552-4

5. Brdicka T, Pavlistova D, Leo A, Bruyns E, Korinek V, Angelisova P, et al. Phosphoprotein associated with glycosphingolipid-enriched microdomains (PAG), a novel ubiquitously expressed transmembrane adaptor protein, binds the protein tyrosine kinase csk and is involved in regulation of $\mathrm{T}$ cell activation. J Exp Med. (2000) 191:1591-604. doi: 10.1084/jem.191.9.1591

6. Sproul TW, Malapati S, Kim J, Pierce SK. Cutting edge: B cell antigen receptor signaling occurs outside lipid rafts in immature B cells. J Immunol. (2000) 165:6020-3. doi: 10.4049/jimmunol.165.11.6020

7. Alonso MA, Millan, J. The role of lipid rafts in signalling and membrane trafficking in T lymphocytes. J Cell Sci. (2001) 114(Pt 22):3957-65.

8. Allende ML, Proia RL. Simplifying complexity: genetically resculpting glycosphingolipid synthesis pathways in mice to reveal function. Glycoconj J. (2014) 31:613-22. doi: 10.1007/s10719-014-9563-5

9. Sarlieve LL, Zalc B, Neskovic NM, Zanetta JP, Rebel G. Structure and immunological localization of spleen sulfolipid. Biochim Biophys Acta (1984) 795:166-8. doi: 10.1016/0005-2760(84)9 0118-8

10. Kniep B, Flegel WA, Northoff H, Rieber EP. CDw60 glycolipid antigens of human leukocytes: structural characterization and cellular distribution. Blood (1993) 82:1776-86.

11. Fox DA, He X, Abe A, Hollander T, Li LL, Kan L, et al. The T lymphocyte structure CD60 contains a sialylated carbohydrate epitope that is expressed on both gangliosides and glycoproteins. Immunol Invest. (2001) 30:67-85. doi: 10.1081/IMM-100104017 allow the community to systemically investigate the role of individual GSLs in immune cells.

\section{AUTHOR CONTRIBUTIONS}

TZ and AdW contributed equally to the writing. MW and RS conceived and edited the manuscript. All authors read and approved the final manuscript.

\section{FUNDING}

This work has received support from the European Union's Horizon 2020 research and innovation programme under the Marie Sklodowska-Curie project GlyCoCan (grant agreement number 676421; MW), from the Netherlands organization for scientific research (ZonMw-ETH 435004024; RS) and from KWF Alpe d'HuZes (Bas Mulder Award; RS).

\section{SUPPLEMENTARY MATERIAL}

The Supplementary Material for this article can be found online at: https://www.frontiersin.org/articles/10.3389/fimmu. 2019.00090/full\#supplementary-material

12. Erdmann M, Wipfler D, Merling A, Cao Y, Claus C, Kniep B, et al. Differential surface expression and possible function of 9-O- and 7-O-acetylated GD3 (CD60 b and c) during activation and apoptosis of human tonsillar B and T lymphocytes. Glycoconj J. (2006) 23:627-38. doi: 10.1007/s10719-006-9000-5

13. Wipfler D, Srinivasan GV, Sadick H, Kniep B, Arming S, WillhauckFleckenstein $\mathrm{M}$, et al. Differentially regulated expression of 9-O-acetyl GD3 (CD60b) and 7-O-acetyl-GD3 (CD60c) during differentiation and maturation of human T and B lymphocytes. Glycobiology (2011) 21:1161-72. doi: $10.1093 /$ glycob/cwr050

14. Yu RK, Bieberich E, Xia T, Zeng G. Regulation of ganglioside biosynthesis in the nervous system. J Lipid Res. (2004) 45:783-93. doi: 10.1194/jlr.R300020-JLR200

15. Zeng G, Yu RK. Cloning and transcriptional regulation of genes responsible for synthesis of gangliosides. Curr Drug Targets (2008) 9:317-24. doi: 10.2174/138945008783954925

16. Maccioni HJ, Quiroga R, Spessott W. Organization of the synthesis of glycolipid oligosaccharides in the Golgi complex. FEBS Lett. (2011) 585:1691-8. doi: 10.1016/j.febslet.2011.03.030

17. Gabius HJ, Kaltner H, Kopitz J, Andre S. The glycobiology of the CD system: a dictionary for translating marker designations into glycan/lectin structure and function. Trends Biochem Sci. (2015) 40:360-76. doi: 10.1016/j.tibs.2015.03.013

18. Giebel B, Corbeil D, Beckmann J, Hohn J, Freund D, Giesen K, et al. Segregation of lipid raft markers including CD133 in polarized human hematopoietic stem and progenitor cells. Blood (2004) 104:2332-8. doi: 10.1182/blood-2004-02-0511

19. Suila H, Pitkanen V, Hirvonen T, Heiskanen A, Anderson H, Laitinen A, et al. Are globoseries glycosphingolipids SSEA-3 and-4 markers for stem cells derived from human umbilical cord blood? J Mol Cell Biol. (2011) 3:99-107. doi: 10.1093/jmcb/mjq041

20. Buehler J, Qwan E, DeGregorio MW, Macher BA. Biosynthesis of glycosphingolipids by human myeloid leukemia cells. Biochemistry (1985) 24:6978-84. doi: 10.1021/bi00345a034

21. Nojiri H, Takaku F, Ohta M, Miura Y, Saito M. Changes in glycosphingolipid composition during differentiation of human leukemic granulocytes in chronic myelogenous leukemia compared with in vitro granulocytic 
differentiation of human promyelocytic leukemia cell line HL-60. Cancer Res (1985) 45(12 Pt 1):6100-6.

22. Saito M. [Bioactive sialoglycosphingolipids (gangliosides): differentiationinducers as well as differentiation-markers in human hematopoietic cells]. Hum Cell (1989) 2:35-44.

23. Cooling LL, Zhang DS, Naides SJ, Koerner TA. Glycosphingolipid expression in acute nonlymphocytic leukemia: common expression of shiga toxin and parvovirus B19 receptors on early myeloblasts. Blood (2003) 101:711-21. doi: 10.1182/blood-2002-03-0718

24. Ziulkoski AL, Andrade CM, Crespo PM, Sisti E, Trindade VM, Daniotti JL, et al. Gangliosides of myelosupportive stroma cells are transferred to myeloid progenitors and are required for their survival and proliferation. Biochem $J$. (2006) 394(Pt 1):1-9. doi: 10.1042/BJ20051189

25. Zuberbier T, Guhl S, Hantke T, Hantke C, Welker P, Grabbe $\mathrm{J}$, et al. Alterations in ganglioside expression during the differentiation of human mast cells. Exp Dermatol. (1999) 8:380-7. doi: 10.1111/j.1600-0625.1999.tb00386.x

26. Ren S, Kambe N, Du Z, Li Y, Xia HZ, Kambe M, et al. Disialoganglioside GD3 is selectively expressed by developing and mature human mast cells. J Allergy Clin Immunol. (2001) 107:322-30. doi: 10.1067/mai.2001.112272

27. Katz HR, Schwarting GA, LeBlanc PA, Austen KF, Stevens RL. Identification of the neutral glycosphingolipids of murine mast cells: expression of Forssman glycolipid by the serosal but not the bone marrow-derived subclass. J Immunol. (1985) 134:2617-23.

28. Katz HR, Austen KF. Plasma membrane and intracellular expression of globotetraosylceramide (globoside) in mouse bone marrow-derived mast cells. J Immunol. (1986) 136:3819-24.

29. Katz HR, Levine JS, Austen KF. Interleukin 3-dependent mouse mast cells express the cholera toxin-binding acidic glycosphingolipid, ganglioside $\mathrm{GM} 1$, and increase their histamine content in response to toxin. J Immunol. (1987) 139:1640-6.

30. Raizman MB, Austen KF, Katz HR. Mast cell heterogeneity. Differential synthesis and expression of glycosphingolipids by mouse serosal mast cells as compared to IL-3-dependent bone marrow culture-derived mast cells before or after coculture with 3T3 fibroblasts. J Immunol. (1990) 145:1463-8.

31. Macher BA, Klock JC. Isolation and chemical characterization of neutral glycosphingolipids of human neutrophils. J Biol Chem. (1980) 255:2092-6.

32. Macher BA, Klock JC, Fukuda MN, Fukuda M. Isolation and structural characterization of human lymphocyte and neutrophil gangliosides. J Biol Chem. (1981) 256:1968-74.

33. Kiguchi K, Iwamori M, Nagai Y, Eto Y, Akatsuka J. Characterization of glycosphingolipids from cells of various types of human leukemia: occurrence of two glycosphingolipids, one reacting with anti-asialo GM1 antibody and one with anti-Forssman antibody. Gan (1983) 74:382-90.

34. Siddiqui B, Buehler J, DeGregorio MW, Macher BA. Differential expression of ganglioside GD3 by human leukocytes and leukemia cells. Cancer Res. (1984) 44:5262-5.

35. Fukuda MN, Dell A, Oates JE, Wu P, Klock JC, Fukuda M. Structures of glycosphingolipids isolated from human granulocytes. The presence of a series of linear poly- $\mathrm{N}$-acetyllactosaminylceramide and its significance in glycolipids of whole blood cells. J Biol Chem. (1985) 260:1067-82.

36. Kniep B, Monner DA, Schwulera U, Muhlradt PF. Glycosphingolipids of the globo-series are associated with the monocytic lineage of human myeloid cells. Eur J Biochem. (1985) 149:187-91. doi: 10.1111/j.1432-1033.1985.tb08910.x

37. Muthing J, Spanbroek R, Peter-Katalinic J, Hanisch FG, Hanski C, Hasegawa A, et al. Isolation and structural characterization of fucosylated gangliosides with linear poly-N-acetyllactosaminyl chains from human granulocytes. Glycobiology (1996) 6:147-56. doi: 10.1093/glycob/6.2.147

38. Karlsson A, Miller-Podraza H, Johansson P, Karlsson KA, Dahlgren C, Teneberg S. Different glycosphingolipid composition in human neutrophil subcellular compartments. Glycoconj J. (2001) 18:231-43. doi: 10.1023/A:1013183124004

39. Iwabuchi K, Nagaoka I. Lactosylceramide-enriched glycosphingolipid signaling domain mediates superoxide generation from human neutrophils. Blood (2002) 100:1454-64.

40. Sheriff A, Gaipl US, Franz S, Heyder P, Voll RE, Kalden JR, et al. Loss of GM1 surface expression precedes annexin V-phycoerythrin binding of neutrophils undergoing spontaneous apoptosis during in vitro aging. Cytometry A (2004) 62:75-80. doi: 10.1002/cyto.a.20090

41. Ackerman GA, Wolken KW, Gelder FB. Surface distribution of monosialoganglioside GM1 on human blood cells and the effect of exogenous GM1 and neuraminidase on cholera toxin surface labeling. A quantitative immunocytochemical study. J Histochem Cytochem. (1980) 28:1100-12. doi: $10.1177 / 28.10 .6775025$

42. Ackerman GA, Wolken KW, Gelder FB. Differential expression of surface monosialoganglioside GM1 in various hemic cell lines of normal human bone marrow. A quantitative immunocytochemical study using the cholera toxin-gold-labeled anti-cholera toxin procedure. J Histochem Cytochem. (1980) 28:1334-42. doi: 10.1177/28.12.7014713

43. Nishikado H, Mukai K, Kawano Y, Minegishi Y, Karasuyama $H$. NK cell-depleting anti-asialo GM1 antibody exhibits a lethal offtarget effect on basophils in vivo. J Immunol. (2011) 186:5766-71. doi: $10.4049 /$ jimmunol.1100370

44. Uemura K, Macher BA, DeGregorio M, Scudder P, Buehler J, Knapp W, et al. Glycosphingolipid carriers of carbohydrate antigens of human myeloid cells recognized by monoclonal antibodies. Biochim Biophys Acta (1985) 846:26-36. doi: 10.1016/0167-4889(85)90106-5

45. Kiguchi K, Henning-Chubb CB, Huberman E. Glycosphingolipid patterns of peripheral blood lymphocytes, monocytes, and granulocytes are cell specific. J Biochem. (1990) 107:8-14. doi: 10.1093/oxfordjournals.jbchem.a123016

46. Gracheva EV, Samovilova NN, Golovanova NK, Andreeva ER, Andrianova IV, Tararak EM, et al. Activation of ganglioside GM3 biosynthesis in human monocyte/macrophages during culturing in vitro. Biochemistry (2007) 72:772-7. doi: 10.1134/S0006297907070127

47. Porubsky S, Speak AO, Luckow B, Cerundolo V, Platt FM, Grone HJ. Normal development and function of invariant natural killer $\mathrm{T}$ cells in mice with isoglobotrihexosylceramide (iGb3) deficiency. Proc Natl Acad Sci USA. (2007) 104:5977-82. doi: 10.1073/pnas.0611139104

48. Delannoy CP, Rombouts Y, Groux-Degroote S, Holst S, Coddeville B, Harduin-Lepers A, et al. Glycosylation Changes Triggered by the Differentiation of Monocytic THP-1 Cell Line into Macrophages. J Proteome Res. (2017) 16:156-69. doi: 10.1021/acs.jproteome.6b00161

49. Nojiri H, Takaku F, Terui Y, Miura Y, Saito M. Ganglioside GM3: an acidic membrane component that increases during macrophage-like cell differentiation can induce monocytic differentiation of human myeloid and monocytoid leukemic cell lines HL-60 and U937. Proc Natl Acad Sci USA. (1986) 83:782-6. doi: 10.1073/pnas.83.3.782

50. Kniep B, Claus C, Peter-Katalinic J, Monner DA, Dippold W, Nimtz M. 7-O-acetyl-GD3 in human T-lymphocytes is detected by a specific Tcell-activating monoclonal antibody. J Biol Chem. (1995) 270:30173-80. doi: $10.1074 /$ jbc.270.50.30173

51. Yohe HC, Wallace PK, Berenson CS, Ye S, Reinhold BB, Reinhold VN. The major gangliosides of human peripheral blood monocytes/macrophages: absence of ganglio series structures. Glycobiology (2001) 11:831-41. doi: $10.1093 /$ glycob/11.10.831

52. Mobarak E, Haversen L, Manna M, Rutberg M, Levin M, Perkins R, et al. Glucosylceramide modifies the LPS-induced inflammatory response in macrophages and the orientation of the LPS/TLR4 complex in silico. Sci Rep. (2018) 8:13600. doi: 10.1038/s41598-018-31926-0

53. Bethke U, Kniep B, Muhlradt PF. Forssman glycolipid, an antigenic marker for a major subpopulation of macrophages from murine spleen and peripheral lymph nodes. J Immunol. (1987) 138:4329-35.

54. Sadahira Y, Mori M, Awai M, Watarai S, Yasuda T. Forssman glycosphingolipid as an immunohistochemical marker for mouse stromal macrophages in hematopoietic foci. Blood (1988) 72:42-8.

55. Bax M, Garcia-Vallejo JJ, Jang-Lee J, North SJ, Gilmartin TJ, Hernandez G, et al. Dendritic cell maturation results in pronounced changes in glycan expression affecting recognition by siglecs and galectins. J Immunol. (2007) 179:8216-24. doi: 10.4049/jimmunol.179.12.8216

56. Puryear WB, Gummuluru S. Role of glycosphingolipids in dendritic cellmediated HIV-1 trans-infection. Adv Exp Med Biol. (2013) 762:131-53. doi: 10.1007/978-1-4614-4433-6_5

57. Li Y, Thapa P, Hawke D, Kondo Y, Furukawa K, Furukawa K, et al. Immunologic glycosphingolipidomics and NKT cell development in mouse thymus. J Proteome Res. (2009) 8:2740-51. doi: 10.1021/pr801040h 
58. Stein KE, Marcus DM. Glycosphingolipids of purified human lymphocytes. Biochemistry (1977) 16:5285-91. doi: 10.1021/bi00643a019

59. Lee WM, Klock JC, Macher BA. Isolation and structural characterization of human lymphocyte neutral glycosphingolipids. Biochemistry (1981) 20:3810-4. doi: 10.1021/bi00516a022

60. Gregory CD, Tursz T, Edwards CF, Tetaud C, Talbot M, Caillou B, et al. Identification of a subset of normal B cells with a Burkitt's lymphoma (BL)-like phenotype. J Immunol. (1987) 139:313-8.

61. Schwartz-Albiez R, Dorken B, Moller P, Brodin NT, Monner DA, Kniep B. Neutral glycosphingolipids of the globo-series characterize activation stages corresponding to germinal center B cells. Int Immunol. (1990) 2:929-36. doi: 10.1093/intimm/2.10.929

62. Madassery, J. V., Gillard, B., Marcus, D. M., and Nahm, M. H. (1991). Subpopulations of B cells in germinal centers. III. HJ6, a monoclonal antibody, binds globoside and a subpopulation of germinal center B cells. J Immunol. 147:823-9.

63. Wiels J, Mangeney M, Tetaud C, Tursz T. Sequential shifts in the three major glycosphingolipid series are associated with $\mathrm{B}$ cell differentiation. Int Immunol. (1991) 3:1289-300. doi: 10.1093/intimm/3.12.1289

64. Stults CL, Macher BA. Beta 1-3-N-acetylglucosaminyltransferase in human leukocytes: properties and role in regulating neolacto glycosphingolipid biosynthesis. Arch Biochem Biophys. (1993) 303:125-33. doi: 10.1006/abbi.1993.1263

65. Tan AH, Sanny A, Ng SW, Ho YS, Basri N, Lee AP, et al. Excessive interferonalpha signaling in autoimmunity alters glycosphingolipid processing in $\mathrm{B}$ cells. J Autoimmun. (2018) 89:53-62. doi: 10.1016/j.jaut.2017.11.004

66. Rosenfelder G, Ziegler A, Wernet P, Braun DG. Ganglioside patterns: new biochemical markers for human hematopoietic cell lines. J Natl Cancer Inst. (1982) 68:203-9.

67. McDonald G, Deepak S, Miguel L, Hall CJ, Isenberg DA, Magee AI, et al. Normalizing glycosphingolipids restores function in CD4+ T cells from lupus patients. J Clin Invest. (2014) 124:712-24. doi: 10.1172/JCI69571

68. Muthing J, Schwinzer B, Peter-Katalinic J, Egge H, Muhlradt PF. Gangliosides of murine T lymphocyte subpopulations. Biochemistry (1989) 28:2923-9. doi: 10.1021/bi00433a027

69. Moore ML, Chi MH, Goleniewska K, Durbin JE, Peebles RS Jr. Differential regulation of GM1 and asialo-GM1 expression by T cells and natural killer (NK) cells in respiratory syncytial virus infection. Viral Immunol. (2008) 21:327-39. doi: 10.1089/vim.2008.0003

70. Nagafuku M, Okuyama K, Onimaru Y, Suzuki A, Odagiri Y, Yamashita $\mathrm{T}$, et al. CD4 and CD8 $\mathrm{T}$ cells require different membrane gangliosides for activation. Proc Natl Acad Sci USA. (2012) 109:E336-42. doi: $10.1073 /$ pnas. 1114965109

71. Inokuchi J, Nagafuku M, Ohno I, Suzuki A. Distinct selectivity of gangliosides required for $\mathrm{CD} 4(+) \mathrm{T}$ and $\mathrm{CD} 8(+) \mathrm{T}$ cell activation. Biochim Biophys Acta (2015) 1851:98-106. doi: 10.1016/j.bbalip.2014.07.013

72. Reivinen J, Holthofer H, Miettinen A. O-acetyl GD3 ganglioside in human peripheral blood T lymphocytes. Int Immunol. (1994) 6:1409-16. doi: 10.1093/intimm/6.9.1409

73. Beck BN, Gillis S, Henney CS. Display of the neutral glycolipid ganglio-ntetraosylceramide (asialo GM1) on cells of the natural killer and T lineages. Transplantation (1982) 33:118-22. doi: 10.1097/00007890-198202000-00003

74. Silvennoinen O, Renkonen R, Hurme M. Characterization of natural killer cells and their precursors in the murine bone marrow. Cell Immunol. (1986) 101:1-7. doi: 10.1016/0008-8749(86)90180-2

75. Yu RK, Suzuki Y, Yanagisawa M. Membrane glycolipids in stem cells. FEBS Lett. (2010) 584:1694-9. doi: 10.1016/j.febslet.2009.08.026

76. Yamazaki S, Iwama A, Takayanagi S, Morita Y, Eto K, Ema H, et al. Cytokine signals modulated via lipid rafts mimic niche signals and induce hibernation in hematopoietic stem cells. EMBO J. (2006) 25:3515-23. doi: $10.1038 /$ sj.emboj.7601236

77. Yamazaki S, Iwama A, Morita Y, Eto K, Ema H, Nakauchi H. Cytokine signaling, lipid raft clustering, and HSC hibernation. Ann N Y Acad Sci. (2007) 1106:54-63. doi: 10.1196/annals.1392.017

78. Chae HD, Lee KE, Williams DA, Gu Y. Cross-talk between RhoH and Rac1 in regulation of actin cytoskeleton and chemotaxis of hematopoietic progenitor cells. Blood (2008) 111:2597-605. doi: 10.1182/blood-2007-06-0 93237
79. Cao Y, Merling A, Karsten U, Schwartz-Albiez R. The fucosylated histo-blood group antigens $\mathrm{H}$ type 2 (blood group O, CD173) and Lewis Y (CD174) are expressed on $\mathrm{CD} 34+$ hematopoietic progenitors but absent on mature lymphocytes. Glycobiology (2001) 11:677-83. doi: 10.1093/glycob/11.8.677

80. Young WW Jr, Hakomori SI, Durdik JM, Henney CS. Identification of ganglio-N-tetraosylceramide as a new cell surface marker for murine natural killer (NK) cells. J Immunol. (1980) 124:199-201.

81. Bordessoule D, Jones M, Gatter KC, Mason DY. Immunohistological patterns of myeloid antigens: tissue distribution of CD13, CD14, CD16, CD31, CD36, CD65, CD66 and CD67. Br J Haematol. (1993) 83:370-83. doi: 10.1111/j.1365-2141.1993.tb04659.x

82. Ossenkoppele GJ, van de Loosdrecht AA, Schuurhuis GJ. Review of the relevance of aberrant antigen expression by flow cytometry in myeloid neoplasms. $\mathrm{Br} J$ Haematol. (2011) 153:421-36. doi: $10.1111 / j .1365-2141.2011 .08595 . x$

83. Siddiqui B, Hakomori S. A revised structure for the Forssman glycolipid hapten. J Biol Chem. (1971) 246:5766-9.

84. Katz HR, Dayton ET, Levi-Schaffer F, Benson AC, Austen KF, Stevens RL. Coculture of mouse IL-3-dependent mast cells with 3T3 fibroblasts stimulates synthesis of globopentaosylceramide (Forssman glycolipid) by fibroblasts and surface expression on both populations. J Immunol. (1988) 140:3090-7.

85. Hanada E, Handa S, Konno K, Yamakawa T. Characterization of glycolipids from rat granuloma and macrophage. J Biochem. (1978) 83:85-90. doi: 10.1093/oxfordjournals.jbchem.a131915

86. Stroud MR, Handa K, Salyan ME, Ito K, Levery SB, Hakomori S, et al. Monosialogangliosides of human myelogenous leukemia HL60 cells and normal human leukocytes. 2. Characterization of E-selectin binding fractions, and structural requirements for physiological binding to E-selectin. Biochemistry (1996) 35:770-8. doi: 10.1021/bi952461g

87. Stroud MR, Handa K, Salyan ME, Ito K, Levery SB, Hakomori S, et al. Monosialogangliosides of human myelogenous leukemia HL60 cells and normal human leukocytes. 1. Separation of E-selectin binding from nonbinding gangliosides, and absence of sialosyl-Le(x) having tetraosyl to octaosyl core. Biochemistry (1996) 35:758-69. doi: 10.1021/bi951600r

88. Smolenska-Sym G, Spychalska J, Zdebska E, Wozniak J, Traczyk Z, Pszenna $\mathrm{E}$, et al. Ceramides and glycosphingolipids in maturation process: leukemic cells as an experimental model. Blood Cells Mol Dis. (2004) 33:68-76. doi: 10.1016/j.bcmd.2004.04.002

89. Momoi T, Shinmoto M, Kasuya J, Senoo H, Suzuki Y. Activation of CMP-N-acetylneuraminic acid:lactosylceramide sialyltransferase during the differentiation of HL-60 cells induced by 12-O-tetradecanoylphorbol-13acetate. J Biol Chem. (1986) 261:16270-3.

90. Symington FW, Murray WA, Bearman SI, Hakomori S. Intracellular localization of lactosylceramide, the major human neutrophil glycosphingolipid. J Biol Chem. (1987) 262:11356-63.

91. Kniep B, Skubitz KM. Subcellular localization of glycosphingolipids in human neutrophils. J Leukoc Biol. (1998) 63:83-8. doi: 10.1002/jlb.63.1.83

92. Banchereau J, Steinman RM. Dendritic cells and the control of immunity. Nature (1998) 392:245-52. doi: 10.1038/32588

93. Mellman I. Dendritic cells: master regulators of the immune response. Cancer Immunol Res. (2013) 1:145-9. doi: 10.1158/2326-6066.CIR-13-0102

94. Hammache D, Yahi N, Maresca M, Pieroni G, Fantini J. Human erythrocyte glycosphingolipids as alternative cofactors for human immunodeficiency virus type 1 (HIV-1) entry: evidence for CD4-induced interactions between HIV-1 gp120 and reconstituted membrane microdomains of glycosphingolipids (Gb3 and GM3). J Virol. (1999) 73:5244-8.

95. Hakomori S. Structure, organization, and function of glycosphingolipids in membrane. Curr Opin Hematol. (2003) 10:16-24. doi: 10.1097/00062752-200301000-00004

96. Gracheva EV, Samovilova NN, Golovanova NK, Kashirina SV, Shevelev A, Rybalkin I, et al. Enhancing of GM3 synthase expression during differentiation of human blood monocytes into macrophages as in vitro model of GM3 accumulation in atherosclerotic lesion. Mol Cell Biochem. (2009) 330:121-9. doi: 10.1007/s11010-009-0125-2

97. Liang F, Seyrantepe V, Landry K, Ahmad R, Ahmad A, Stamatos NM, et al. Monocyte differentiation up-regulates the expression of the lysosomal sialidase, Neul, and triggers its targeting to the plasma membrane via major 
histocompatibility complex class II-positive compartments. J Biol Chem. (2006) 281:27526-38. doi: 10.1074/jbc.M605633200

98. Wang D, Ozhegov E, Wang L, Zhou A, Nie H, Li Y, et al. Sialylation and desialylation dynamics of monocytes upon differentiation and polarization to macrophages. Glycoconj J. (2016) 33:725-33. doi: 10.1007/s10719-016-9664-4

99. Ramegowda B, Tesh VL. Differentiation-associated toxin receptor modulation, cytokine production, and sensitivity to Shiga-like toxins in human monocytes and monocytic cell lines. Infect Immun. (1996) 64:1173-80.

100. Akagawa KS, Momoi T, Nagai Y, Tokunaga T. Appearance of asialo GM1 glycosphingolipid on the cell surface during lymphokineinduced differentiation of M1 cells. FEBS Lett. (1981) 130:80-4. doi: 10.1016/0014-5793(81)80670-9

101. Yang SS, Malek TR, Hargrove ME, Ting CC. Lymphokine-induced cytotoxicity: requirement of two lymphokines for the induction of optimal cytotoxic response. J Immunol. (1985) 134:3912-9.

102. Ting CC, Hargrove ME, Wunderlich J, Loh NN. Differential expression of asialo GM1 on alloreactive cytotoxic T lymphocytes and lymphokine-activated killer cells. Cell Immunol. (1987) 104:115-25. doi: 10.1016/0008-8749(87)90012-8

103. Mercurio AM, Schwarting GA, Robbins PW. Glycolipids of the mouse peritoneal macrophage. Alterations in amount and surface exposure of specific glycolipid species occur in response to inflammation and tumoricidal activation. J Exp Med. (1984) 160:1114-25. doi: 10.1084/jem.160.4.1114

104. von Kleist R, Schmitt E, Westermann J, Muhlradt PF. Modulation of Forssman glycosphingolipid expression by murine macrophages: coinduction with class II MHC antigen by the lymphokines IL4 and IL6. Immunobiology (1990) 180:405-18. doi: 10.1016/S0171-2985(11)80302-5

105. Monner DA, Muhlradt PF. Surface expression of Forssman glycosphingolipid antigen on murine bone marrow-derived macrophages is subject to both temporal and population-specific regulation and is modulated by IL-4 and IL-6. Immunobiology (1993) 188:82-98. doi: 10.1016/S0171-2985(11)80489-4

106. Zhou D, Mattner J, Cantu C III, Schrantz N, Yin N, Gao Y, et al. Lysosomal glycosphingolipid recognition by NKT cells. Science (2004) 306:1786-9. doi: $10.1126 /$ science. 1103440

107. Salio M, Speak AO, Shepherd D, Polzella P, Illarionov PA, Veerapen N, et al. Modulation of human natural killer T cell ligands on TLR-mediated antigenpresenting cell activation. Proc Natl Acad Sci USA. (2007) 104:20490-5. doi: 10.1073/pnas.0710145104

108. Speak AO, Salio M, Neville DC, Fontaine J, Priestman DA, Platt N, et al. Implications for invariant natural killer $\mathrm{T}$ cell ligands due to the restricted presence of isoglobotrihexosylceramide in mammals. Proc Natl Acad Sci USA. (2007) 104:5971-6. doi: 10.1073/pnas.0607285104

109. Prigozy TI, Naidenko O, Qasba P, Elewaut D, Brossay L, Khurana A, et al. Glycolipid antigen processing for presentation by CD1d molecules. Science (2001) 291:664-7. doi: 10.1126/science.291.5504.664

110. Nohara K, Nakauchi H, Spiegel S. Glycosphingolipids of rat $\mathrm{T}$ cells. Predominance of asialo-GM1 and GD1c. Biochemistry (1994) 33:4661-6. doi: 10.1021/bi00181a601

111. Mangeney M, Richard Y, Coulaud D, Tursz T, Wiels J. CD77: an antigen of germinal center B cells entering apoptosis. Eur J Immunol. (1991) 21:113140. doi: $10.1002 /$ eji. 1830210507

112. Hogerkorp CM, Borrebaeck CA. The human CD77- B cell population represents a heterogeneous subset of cells comprising centroblasts, centrocytes, and plasmablasts, prompting phenotypical revision. J Immunol. (2006) 177:4341-9. doi: 10.4049/jimmunol.177.7.4341

113. Menge C, Stamm I, Wuhrer M, Geyer R, Wieler LH, Baljer G. Globotriaosylceramide $(\mathrm{Gb}(3) / \mathrm{CD} 77)$ is synthesized and surface expressed by bovine lymphocytes upon activation in vitro. Vet Immunol Immunopathol. (2001) 83:19-36. doi: 10.1016/S0165-2427(01)0 0365-8

114. Taga S, Tetaud C, Mangeney M, Tursz T, Wiels J. Sequential changes in glycolipid expression during human B cell differentiation: enzymatic bases. Biochim Biophys Acta (1995) 1254:56-65. doi: 10.1016/0005-2760(94)00167-W
115. Sorice M, Parolini I, Sansolini T, Garofalo T, Dolo V, Sargiacomo M, et al. Evidence for the existence of ganglioside-enriched plasma membrane domains in human peripheral lymphocytes. J Lipid Res. (1997) 38:969-80.

116. Garofalo T, Sorice M, Misasi R, Cinque B, Giammatteo M, Pontieri GM, et al. A novel mechanism of CD4 down-modulation induced by monosialoganglioside GM3. Involvement of serine phosphorylation and protein kinase c delta translocation. J Biol Chem. (1998) 273:35153-60. doi: $10.1074 /$ jbc. 273.52 .35153

117. Cho JH, Kim HO, Surh CD, Sprent J. T cell receptor-dependent regulation of lipid rafts controls naive CD8+ T cell homeostasis. Immunity (2010) 32:214-26. doi: 10.1016/j.immuni.2009.11.014

118. Richard EM, Thiyagarajan T, Bunni MA, Basher F, Roddy PO, Siskind LJ, et al. Reducing FLI1 levels in the MRL/lpr lupus mouse model impacts T cell function by modulating glycosphingolipid metabolism. PLoS ONE (2013) 8:e75175. doi: 10.1371/journal.pone.0075175

119. Villanueva-Cabello TM, Mollicone R, Cruz-Munoz ME, LopezGuerrero DV, Martinez-Duncker I. Activation of human naive Th cells increases surface expression of GD3 and induces neoexpression of GD2 that colocalize with TCR clusters. Glycobiology (2015) 25:1454-64. doi: 10.1093/glycob/cwv062

120. Wang P, Zhang J, Bian H, Wu P, Kuvelkar R, Kung TT, et al. Induction of lysosomal and plasma membrane-bound sialidases in human T-cells via T-cell receptor. Biochem J (2004) 380(Pt 2):425-33. doi: 10.1042/bj20031896

121. Nan X, Carubelli I, Stamatos NM. Sialidase expression in activated human T lymphocytes influences production of IFN-gamma. J Leukoc Biol. (2007) 81:284-96. doi: 10.1189/jlb.1105692

122. Muthing J, Egge H, Kniep B, Muhlradt PF. Structural characterization of gangliosides from murine T lymphocytes. Eur J Biochem. (1987) 163:407-16. doi: 10.1111/j.1432-1033.1987.tb10813.x

123. Nakamura K, Suzuki H, Hirabayashi Y, Suzuki A. IV3 alpha (NeuGc alpha $2-8 \mathrm{NeuGc}$ - $\mathrm{Gg} 4 \mathrm{Cer}$ is restricted to CD4+ T cells producing interleukin-2 and a small population of mature thymocytes in mice. J Biol Chem. (1995) 270:3876-81. doi: 10.1074/jbc.270.8.3876

124. Takamiya K, Yamamoto A, Furukawa K, Yamashiro S, Shin M, Okada $\mathrm{M}$, et al. Mice with disrupted GM2/GD2 synthase gene lack complex gangliosides but exhibit only subtle defects in their nervous system. Proc Natl Acad Sci USA. (1996) 93:10662-7. doi: 10.1073/pnas.93.20.10662

125. Marusic A, Markotic A, Kovacic N, Muthing J. Expression of glycosphingolipids in lymph nodes of mice lacking TNF receptor 1: biochemical and flow cytometry analysis. Carbohydr Res. (2004) 339:77-86. doi: 10.1016/j.carres.2003.09.024

126. Wang J, Lu ZH, Gabius HJ, Rohowsky-Kochan C, Ledeen RW, Wu G. Cross-linking of GM1 ganglioside by galectin-1 mediates regulatory $\mathrm{T}$ cell activity involving TRPC5 channel activation: possible role in suppressing experimental autoimmune encephalomyelitis. J Immunol. (2009) 182:403645. doi: 10.4049/jimmunol.0802981

127. Ebel F, Schmitt E, Peter-Katalinic J, Kniep B, Muhlradt PF. Gangliosides: differentiation markers for murine Thelper lymphocyte subpopulations TH1 and TH2. Biochemistry (1992) 31:12190-7. doi: 10.1021/bi00163a031

128. Amado M, Yan Q, Comelli EM, Collins BE, Paulson JC. Peanut agglutinin high phenotype of activated CD8+ $\mathrm{T}$ cells results from de novo synthesis of CD45 glycans. J Biol Chem. (2004) 279:36689-97. doi: 10.1074/jbc.M405629200

129. Nohara K, Suzuki M, Inagaki F, Sano T, Kaya K. A novel disialoganglioside in rat spleen lymphocytes. J Biol Chem. (1992) 267:14982-6.

130. Habu S, Kasai M, Nagai Y, Tamaoki N, TAda T, Herzenberg LA, et al. The glycolipid asialo GM1 as a new differentiation antigen of fetal thymocytes. $J$ Immunol. (1980) 125:2284-8.

131. Arndt R, Thiele HG, Hamann A, Graning G, Raedler A, Momoi T, et al. Studies on the nature and cellular distribution of TLMA-a major rat $\mathrm{T}$ axis differentiation antigen. Identification as the glycosphingolipid GgOse4Cer (asialo GM1). Eur J Immunol. (1981) 11:21-26. doi: 10.1002/eji.1830110106

132. Teneberg S, Berntsson A, Angstrom J. Common architecture of the primary galactose binding sites of Erythrina corallodendron lectin and heat-labile enterotoxin from Escherichia coli in relation to the binding of branched neolactohexaosylceramide. J Biochem. (2000) 128:481-91. doi: 10.1093/oxfordjournals.jbchem.a022778 
133. Sadahira Y, Yasuda T, Kimoto T. Regulation of Forssman antigen expression during maturation of mouse stromal macrophages in haematopoietic foci. Immunology (1991) 73:498-504.

134. Jha AK, Huang SC, Sergushichev A, Lampropoulou V, Ivanova Y, Loginicheva E, et al. Network integration of parallel metabolic and transcriptional data reveals metabolic modules that regulate macrophage polarization. Immunity (2015) 42:419-30. doi: 10.1016/j.immuni.2015.02.005

135. Tsunoda A, Nakamura M, Kirito K, Hara K, Saito M. Interleukin-3associated expression of gangliosides in mouse myelogenous leukemia NFS60 cells introduced with interleukin-3 gene: expression of ganglioside GD1a and key involvement of CMP-NeuAc:lactosylceramide alpha 2->3sialyltransferase in GD1a expression. Biochemistry (1995) 34:9356-67.

136. Kolesnick RN, Kronke M. Regulation of ceramide production and apoptosis. Annu Rev Physiol. (1998) 60:643-65. doi: 10.1146/annurev.physiol.60.1.643

137. Colell A, Morales A, Fernandez-Checa JC, Garcia-Ruiz C. (2002). Ceramide generated by acidic sphingomyelinase contributes to tumor necrosis factor-alpha-mediated apoptosis in human colon HT-29 cells through glycosphingolipids formation. Possible role of ganglioside GD3. FEBS Lett. 526:135-41. doi: 10.1016/S0014-5793(02)03140-X

138. Eisenhauer PB, Chaturvedi P, Fine RE, Ritchie AJ, Pober JS, Cleary TG, et al. Tumor necrosis factor alpha increases human cerebral endothelial cell Gb3 and sensitivity to Shiga toxin. Infect Immun. (2001) 69:1889-94. doi: 10.1128/IAI.69.3.1889-1894.2001

139. Tagami S, Inokuchi Ji J, Kabayama K, Yoshimura H, Kitamura F, Uemura S, et al. Ganglioside GM3 participates in the pathological conditions of insulin resistance. J Biol Chem. (2002) 277:3085-92. doi: 10.1074/jbc.M103705200

140. Raval G, Biswas S, Rayman P, Biswas K, Sa G, Ghosh S, et al. TNF-alpha induction of GM2 expression on renal cell carcinomas promotes $\mathrm{T}$ cell dysfunction. J Immunol. (2007) 178:6642-52. doi: 10.4049/jimmunol.178.10.6642

141. Gee K, Kozlowski M, Kumar A. Tumor necrosis factor-alpha induces functionally active hyaluronan-adhesive CD44 by activating sialidase through p38 mitogen-activated protein kinase in lipopolysaccharidestimulated human monocytic cells. J Biol Chem. (2003) 278:37275-87. doi: 10.1074/jbc.M302309200

142. Schwarting GA, Gajewski A. Heparin inhibits specific glycosyltransferase activities in interleukin 2 activated murine T cells. Biosci Rep. (1988) 8:38999. doi: 10.1007/BF01115230

143. Tuosto L, Parolini I, Schroder S, Sargiacomo M, Lanzavecchia A, Viola A. Organization of plasma membrane functional rafts upon T cell activation. Eur J Immunol. (2001) 31:345-9. doi: 10.1002/1521-4141(200102)31:2<345::AID-IMMU345gt;3.0.CO;2-L

144. Nicolson GL. The Fluid-Mosaic Model of Membrane Structure: still relevant to understanding the structure, function and dynamics of biological membranes after more than 40 years. Biochim Biophys Acta (2014) 1838:1451-66. doi: 10.1016/j.bbamem.2013.10.019

145. Montixi C, Langlet C, Bernard AM, Thimonier J, Dubois C, Wurbel $\mathrm{MA}$, et al. Engagement of T cell receptor triggers its recruitment to lowdensity detergent-insoluble membrane domains. EMBO J. (1998) 17:533448. doi: 10.1093/emboj/17.18.5334

146. Xavier R, Brennan T, Li Q, McCormack C, Seed B. Membrane compartmentation is required for efficient T cell activation. Immunity (1998) 8:723-32. doi: 10.1016/S1074-7613(00)80577-4

147. Zhang $\mathrm{W}$, Trible RP, Samelson LE. LAT palmitoylation: its essential role in membrane microdomain targeting and tyrosine phosphorylation during $\mathrm{T}$ cell activation. Immunity (1998) 9:239-46. doi: 10.1016/S1074-7613(00)80606-8

148. Janes PW, Ley SC, Magee AI. Aggregation of lipid rafts accompanies signaling via the T cell antigen receptor. J Cell Biol. (1999) 147:447-61. doi: $10.1083 /$ jcb.147.2.447

149. Boerth NJ, Sadler JJ, Bauer DE, Clements JL, Gheith SM, Koretzky GA. Recruitment of Slp-76 to the Membrane and Glycolipid-Enriched Membrane Microdomains Replaces the Requirement for Linker for Activation of T Cells in T Cell Receptor Signaling. J Exp Med. (2000) 192:1047-58. doi: 10.1084/jem.192.7.1047

150. Schade AE, Levine AD. Lipid raft heterogeneity in human peripheral blood $\mathrm{T}$ lymphoblasts: a mechanism for regulating the initiation of TCR signal transduction. J Immunol. (2002) 168:2233-9. doi: 10.4049/jimmunol.168.5.2233

151. Kabouridis PS. Lipid rafts in T cell receptor signalling. Mol Membr Biol. (2006) 23:49-57. doi: 10.1080/09687860500453673

152. Popovic ZV, Rabionet M, Jennemann R, Krunic D, Sandhoff R, Grone $\mathrm{HJ}$, et al. Glucosylceramide synthase is involved in development of invariant natural killer T cells. Front Immunol. (2017) 8:848. doi: 10.3389/fimmu.2017.00848

153. Chung JB, Baumeister MA, Monroe JG. Cutting edge: differential sequestration of plasma membrane-associated $\mathrm{B}$ cell antigen receptor in mature and immature B cells into glycosphingolipid-enriched domains. $J$ Immunol. (2001) 166:736-40. doi: 10.4049/jimmunol.166.2.736

154. Klasener K, Maity PC, Hobeika E, Yang J, Reth M. B cell activation involves nanoscale receptor reorganizations and inside-out signaling by Syk. Elife (2014) 3:e02069. doi: 10.7554/eLife.02069

155. Minguet S, Klasener K, Schaffer AM, Fiala GJ, Osteso-Ibanez T, Raute K, et al. Caveolin-1-dependent nanoscale organization of the BCR regulates $\mathrm{B}$ cell tolerance. Nat Immunol. (2017) 18:1150-9. doi: 10.1038/ni.3813

156. Anderson HA, Hiltbold EM, Roche PA. Concentration of MHC class II molecules in lipid rafts facilitates antigen presentation. Nat Immunol. (2000) 1:156-62. doi: 10.1038/77842

157. Gordy C, Mishra S, Rodgers W. Visualization of antigen presentation by actin-mediated targeting of glycolipid-enriched membrane domains to the immune synapse of B cell APCs. J Immunol. (2004) 172:2030-8. doi: 10.4049/jimmunol.172.4.2030

158. Togayachi A, Kozono Y, Ikehara Y, Ito H, Suzuki N, Tsunoda Y, et al. Lack of lacto/neolacto-glycolipids enhances the formation of glycolipid-enriched microdomains, facilitating B cell activation. Proc Natl Acad Sci USA. (2010) 107:11900-5. doi: 10.1073/pnas.0914298107

159. Kabayama K, Sato T, Saito K, Loberto N, Prinetti A, Sonnino S, et al. Dissociation of the insulin receptor and caveolin-1 complex by ganglioside GM3 in the state of insulin resistance. Proc Natl Acad Sci USA. (2007) 104:13678-83. doi: 10.1073/pnas.0703650104

160. Coskun U, Grzybek M, Drechsel D, Simons K. Regulation of human EGF receptor by lipids. Proc Natl Acad Sci USA. (2011) 108:9044-8. doi: $10.1073 /$ pnas. 1105666108

161. Kondo Y, Ikeda K, Tokuda N, Nishitani C, Ohto U, Akashi-Takamura $\mathrm{S}$, et al. TLR4-MD-2 complex is negatively regulated by an endogenous ligand, globotetraosylceramide. Proc Natl Acad Sci USA. (2013) 110:4714-9. doi: $10.1073 /$ pnas. 1218508110

162. Saggioro D, Sorio C, Calderazzo F, Callegaro L, Panozzo M, Berton G, et al. Mechanism of action of the monosialoganglioside GM1 as a modulator of CD4 expression. Evidence that GM1-CD4 interaction triggers dissociation of p56lck from CD4, and CD4 internalization and degradation. J Biol Chem. (1993) 268:1368-75.

163. Barbat C, Trucy M, Sorice M, Garofalo T, Manganelli V, Fischer A, et al. p56lck, LFA-1 and PI3K but not SHP-2 interact with GM1- or GM3-enriched microdomains in a CD4-p56lck association-dependent manner. Biochem J. (2007) 402:471-81. doi: 10.1042/BJ20061061

164. Kawakami Y, Kawakami K, Steelant WF, Ono M, Baek RC, Handa K, et al. Tetraspanin CD9 is a "proteolipid," and its interaction with alpha 3 integrin in microdomain is promoted by GM3 ganglioside, leading to inhibition of laminin-5-dependent cell motility. J Biol Chem. (2002) 277:34349-58. doi: 10.1074/jbc.M200771200

165. Todeschini AR, Dos Santos JN, Handa K, Hakomori SI. Ganglioside GM2tetraspanin CD82 complex inhibits met and its cross-talk with integrins, providing a basis for control of cell motility through glycosynapse. J Biol Chem. (2007) 282:8123-33. doi: 10.1074/jbc.M611407200

166. Zhang $\mathrm{Y}$, Wang $\mathrm{H}$. Integrin signalling and function in immune cells. Immunology (2012) 135:268-75. doi: 10.1111/j.1365-2567.2011.0 3549.x

167. Odintsova E, Butters TD, Monti E, Sprong H, van Meer G, Berditchevski F. Gangliosides play an important role in the organization of CD82enriched microdomains. Biochem J. (2006) 400:315-25. doi: 10.1042/BJ200 60259

168. Odintsova E, Voortman J, Gilbert E, Berditchevski F. Tetraspanin CD82 regulates compartmentalisation and ligand-induced dimerization of EGFR. $J$ Cell Sci. (2003) 116(Pt 22):4557-66. doi: 10.1242/jcs.00793 
169. Maloney MD, Lingwood CA. CD19 has a potential CD77 (globotriaosyl ceramide)-binding site with sequence similarity to verotoxin Bsubunits: implications of molecular mimicry for B cell adhesion and enterohemorrhagic Escherichia coli pathogenesis. J Exp Med. (1994) 180:191-201. doi: 10.1084/jem.180.1.191

170. George T, Boyd B, Price M, Lingwood C, Maloney M. MHC class II proteins contain a potential binding site for the verotoxin receptor glycolipid CD77. Cell Mol Biol. (2001) 47:1179-85.

171. Heuss SF, Tarantino N, Fantini J, Ndiaye-Lobry D, Moretti J, Israel A, et al. A glycosphingolipid binding domain controls trafficking and activity of the mammalian notch ligand delta-like 1. PLoS ONE (2013) 8:e74392. doi: 10.1371/journal.pone.0074392

172. Amsen D, Helbig C, Backer RA. Notch in T cell differentiation: all things considered. Trends Immunol. (2015) 36:802-14. doi: 10.1016/j.it.2015.10.007

173. Chakrabandhu K, Huault S, Garmy N, Fantini J, Stebe E, Mailfert S, et al. The extracellular glycosphingolipid-binding motif of Fas defines its internalization route, mode and outcome of signals upon activation by ligand. Cell Death Differ. (2008) 15:1824-37. doi: 10.1038/cdd.2008.115

174. Wang X, Sun P, Al-Qamari A, Tai T, Kawashima I, Paller AS. Carbohydrate-carbohydrate binding of ganglioside to integrin alpha(5) modulates alpha(5)beta(1) function. J Biol Chem. (2001) 276:8436-44. doi: $10.1074 /$ jbc.M006097200

175. Takayama E, Kina T, Katsura Y, Tadakuma T. Enhancement of activationinduced cell death by fibronectin in murine CD4+ CD8+ thymocytes. Immunology (1998) 95:553-8. doi: 10.1046/j.1365-2567.1998.00636.x

176. Bertoni A, Alabiso O, Galetto AS, Baldanzi G. Integrins in T cell physiology. Int J Mol Sci. (2018) 19:E485. doi: 10.3390/ijms19020485

177. Spiegel S. Inhibition of protein kinase C-dependent cellular proliferation by interaction of endogenous ganglioside GM1 with the B subunit of cholera toxin. J Biol Chem. (1989) 264:16512-7.

178. Klokk TI, Kavaliauskiene S, Sandvig K. Cross-linking of glycosphingolipids at the plasma membrane: consequences for intracellular signaling and traffic. Cell Mol Life Sci. (2016) 73:1301-16. doi: 10.1007/s00018-015-2049-1

179. Higashi H, Omori A, Yamagata T. Calmodulin, a ganglioside-binding protein. Binding of gangliosides to calmodulin in the presence of calcium. J Biol Chem. (1992) 267:9831-8.

180. Carlson RO, Masco D, Brooker G, Spiegel S. Endogenous ganglioside GM1 modulates L-type calcium channel activity in N18 neuroblastoma cells. J Neurosci. (1994) 14:2272-81. doi: 10.1523/JNEUROSCI.14-04-02272.1994

181. Mori T, Kiyokawa N, Katagiri YU, Taguchi T, Suzuki T, Sekino T, et al. Globotriaosyl ceramide $(\mathrm{CD} 77 / \mathrm{Gb} 3)$ in the glycolipid-enriched membrane domain participates in B-cell receptor-mediated apoptosis by regulating lyn kinase activity in human B cells. Exp Hematol. (2000) 28:1260-8. doi: 10.1016/S0301-472X(00)00538-5

182. Mangeney M, Lingwood CA, Taga S, Caillou B, Tursz T, Wiels J. Apoptosis induced in Burkitt's lymphoma cells via Gb3/CD77, a glycolipid antigen. Cancer Res. (1993) 53:5314-9.

183. Taga S, Carlier K, Mishal Z, Capoulade C, Mangeney M, Lecluse Y, et al. Intracellular signaling events in CD77-mediated apoptosis of Burkitt's lymphoma cells. Blood (1997) 90:2757-67.

184. Tetaud C, Falguieres T, Carlier K, Lecluse Y, Garibal J, Coulaud D, et al. Two distinct $\mathrm{Gb} 3 / \mathrm{CD} 77$ signaling pathways leading to apoptosis are triggered by anti-Gb3/CD77 mAb and verotoxin-1. J Biol Chem. (2003) 278:45200-8. doi: $10.1074 /$ jbc.M303868200

185. Debernardi J, Hollville E, Lipinski M, Wiels J, Robert A. Differential role of FL-BID and t-BID during verotoxin-1-induced apoptosis in Burkitt's lymphoma cells. Oncogene (2018) 37:2410-21. doi: 10.1038/s41388-018-0123-5

186. Nashar TO, Williams NA, Hirst TR. Cross-linking of cell surface ganglioside GM1 induces the selective apoptosis of mature CD8+ T lymphocytes. Int Immunol. (1996) 8:731-6. doi: 10.1093/intimm/8.5.731

187. Yoshizaki F, Nakayama H, Iwahara C, Takamori K, Ogawa H, Iwabuchi $\mathrm{K}$. Role of glycosphingolipid-enriched microdomains in innate immunity: microdomain-dependent phagocytic cell functions. Biochim Biophys Acta (2008) 1780:383-92. doi: 10.1016/j.bbagen.2007.11.004

188. Ekyalongo RC, Nakayama H, Kina K, Kaga N, Iwabuchi K. Organization and functions of glycolipid-enriched microdomains in phagocytes. Biochim Biophys Acta (2015) 1851:90-7. doi: 10.1016/j.bbalip.2014.06.009
189. Prinetti A, Marano N, Prioni S, Chigorno V, Mauri L, Casellato R, et al. Association of Src-family protein tyrosine kinases with sphingolipids in rat cerebellar granule cells differentiated in culture. Glycoconj J. (2000) 17:223-32. doi: 10.1023/A:1026545424720

190. Schnaar RL. Glycolipid-mediated cell-cell recognition in inflammation and nerve regeneration. Arch Biochem Biophys. (2004) 426:163-72. doi: 10.1016/j.abb.2004.02.019

191. Aerts-Toegaert C, Heirman C, Tuyaerts S, Corthals J, Aerts JL, Bonehill A, et al. CD83 expression on dendritic cells and T cells: correlation with effective immune responses. Eur J Immunol. (2007) 37:686-95. doi: $10.1002 /$ eji.200636535

192. Scholler N, Hayden-Ledbetter M, Hellstrom KE, Hellstrom I, Ledbetter JA. CD83 Is a Sialic Acid-Binding Ig-Like Lectin (Siglec) adhesion receptor that binds monocytes and a subset of activated CD8+ T cells. J Immunol. (2001) 166:3865-72. doi: 10.4049/jimmunol.166.6.3865

193. Razi N, Varki A. Masking and unmasking of the sialic acid-binding lectin activity of CD22 (Siglec-2) on B lymphocytes. Proc Natl Acad Sci USA. (1998) 95:7469-74. doi: 10.1073/pnas.95.13.7469

194. Razi N, Varki A. Cryptic sialic acid binding lectins on human blood leukocytes can be unmasked by sialidase treatment or cellular activation. Glycobiology (1999) 9:1225-34. doi: 10.1093/glycob/9.11.1225

195. Nicoll G, Avril T, Lock K, Furukawa K, Bovin N, Crocker PR. Ganglioside GD3 expression on target cells can modulate NK cell cytotoxicity via siglec-7dependent and -independent mechanisms. Eur J Immunol. (2003) 33:1642-8. doi: $10.1002 /$ eji.200323693

196. Lopez PH, Schnaar RL. Gangliosides in cell recognition and membrane protein regulation. Curr Opin Struct Biol. (2009) 19:549-57. doi: 10.1016/j.sbi.2009.06.001

197. Lanoue A, Batista FD, Stewart M, Neuberger MS. Interaction of CD22 with alpha2,6-linked sialoglycoconjugates: innate recognition of self to dampen B cell autoreactivity? Eur J Immunol. (2002) 32:348-55. doi: 10.1002/1521-4141(200202)32:2<348::AID-IMMU348>3.0.CO;2-5

198. Zemunik T, Markotic A, Marusic A. Expression of neutral glycosphingolipids in cytokine-stimulated human endothelial cells. Biochemistry (2004) 69:5139. doi: 10.1023/B:BIRY.0000029849.82612.1a

199. Nimrichter L, Burdick MM, Aoki K, Laroy W, Fierro MA, Hudson SA, et al. E-selectin receptors on human leukocytes. Blood (2008) 112:3744-52. doi: 10.1182/blood-2008-04-149641

200. Hakomori S. Carbohydrate-to-carbohydrate interaction, through glycosynapse, as a basis of cell recognition and membrane organization. Glycoconj J. (2004) 21:125-37. doi: 10.1023/B:GLYC.0000044844.95878.cf

201. Kojima N, Hakomori S. Specific interaction between gangliotriaosylceramide (Gg3) and sialosyllactosylceramide (GM3) as a basis for specific cellular recognition between lymphoma and melanoma cells. J Biol Chem. (1989) 264:20159-62.

202. Tromas C, Rojo J, de la Fuente JM, Barrientos AG, Garcia R, Penades $\mathrm{S}$. Adhesion forces between Lewis(X) determinant antigens as measured by atomic force microscopy. Angew Chem Int Ed Engl. (2001) 40:3052-5. doi: 10.1002/1521-3773(20010817)40:16<3052::AID-ANIE3052>3.0.CO;2-Q

203. Toth EA, Oszvald A, Peter M, Balogh G, Osteikoetxea-Molnar A, Bozo T, et al. Nanotubes connecting B lymphocytes: high impact of differentiationdependent lipid composition on their growth and mechanics. Biochim Biophys Acta (2017) 1862:991-1000. doi: 10.1016/j.bbalip.2017.06.011

204. Alam S, Anugraham M, Huang YL, Kohler RS, Hettich T, Winkelbach K, et al. Altered (neo-) lacto series glycolipid biosynthesis impairs alpha26 sialylation on N-glycoproteins in ovarian cancer cells. Sci Rep. (2017) 7:45367. doi: 10.1038/srep45367

205. Bratosin D, Tissier JP, Lapillonne H, Hermine O, de Villemeur TB, Cotoraci $\mathrm{C}$, et al. A cytometric study of the red blood cells in Gaucher disease reveals their abnormal shape that may be involved in increased erythrophagocytosis. Cytometry B Clin Cytom. (2011) 80:28-37. doi: 10.1002/cyto.b.20539

206. Stirnemann J, Belmatoug N, Camou F, Serratrice C, Froissart R, Caillaud $\mathrm{C}$, et al. A review of gaucher disease pathophysiology, clinical presentation and treatments. Int J Mol Sci. (2017) 18:E441. doi: 10.3390/ijms180 20441

207. Furukawa K, Akagi T, Nagata Y, Yamada Y, Shimotohno K, Cheung NK, et al. GD2 ganglioside on human T-lymphotropic virus type I-infected T cells: possible activation of beta-1,4-N-acetylgalactosaminyltransferase 
gene by p40tax. Proc Natl Acad Sci USA. (1993) 90:1972-6. doi: 10.1073/pnas.90.5.1972

208. Radsak K, Wiegandt H. Glycosphingolipid synthesis in human fibroblasts infected by cytomegalovirus. Virology (1984) 138:300-9. doi: 10.1016/0042-6822(84)90353-2

209. Andrews PW. Human cytomegalovirus induces stage-specific embryonic antigen 1 in differentiating human teratocarcinoma cells and fibroblasts. $J$ Exp Med. (1989) 169:1347-59. doi: 10.1084/jem.169.4.1347

210. Miyaji K, Furukawa JI, Suzuki Y, Yamamoto N, Shinohara Y, Yuki N. Altered gene expression of glycosyltransferases and sialyltransferases and total amount of glycosphingolipids following herpes simplex virus infection. Carbohydr Res. (2016) 434:37-43. doi: 10.1016/j.carres.2016.08.004

211. Belotserkovsky I, Brunner K, Pinaud L, Rouvinski A, Dellarole M, Baron B, et al. Glycan-glycan interaction determines shigella tropism toward human T lymphocytes. MBio (2018) 9:e02309-17. doi: 10.1128/mBio.02309-17

212. Day CJ, Tran EN, Semchenko EA, Tram G, Hartley-Tassell LE, Ng PS, et al. Glycan:glycan interactions: high affinity biomolecular interactions that can mediate binding of pathogenic bacteria to host cells. Proc Natl Acad Sci USA. (2015) 112:E7266-75. doi: 10.1073/pnas.1421082112

213. King CA, Van Heyningen WE. Deactivation of cholera toxin by a sialidase-resistant monosialosylganglioside. J Infect Dis. (1973) 127:639-47. doi: 10.1093/infdis/127.6.639

214. Williams NA, Hirst TR, Nashar TO. Immune modulation by the choleralike enterotoxins: from adjuvant to therapeutic. Immunol Today (1999) 20:95-101. doi: 10.1016/S0167-5699(98)01397-8

215. Blank N, Schiller M, Krienke S, Wabnitz G, Ho AD, Lorenz HM. Cholera toxin binds to lipid rafts but has a limited specificity for ganglioside GM1. Immunol Cell Biol. (2007) 85:378-82. doi: 10.1038/sj.icb.7100045

216. Cervin J, Wands AM, Casselbrant A, Wu H, Krishnamurthy S, Cvjetkovic A, et al. GM1 ganglioside-independent intoxication by Cholera toxin. PLoS Pathog. (2018) 14:e1006862. doi: 10.1371/journal.ppat.1006862

217. Lingwood CA. Shiga toxin receptor glycolipid binding. Pathology and utility. Methods Mol Med. (2003) 73:165-86. doi: 10.1385/1-59259-316-x:165

218. Lee RS, Tartour E, van der Bruggen P, Vantomme V, Joyeux I, Goud B, et al. Major histocompatibility complex class I presentation of exogenous soluble tumor antigen fused to the B-fragment of Shiga toxin. Eur I Immunol. (1998) 28:2726-37. doi: 10.1002/(SICI)1521-4141(199809)28:09<2726::AIDIMMU2726>3.0.CO;2-W

219. Jacewicz M, Clausen H, Nudelman E, Donohue-Rolfe A, Keusch GT. Pathogenesis of shigella diarrhea. XI Isolation of a shigella toxin-binding glycolipid from rabbit jejunum and HeLa cells and its identification as globotriaosylceramide. J Exp Med. (1986) 163:1391-404. doi: 10.1084/jem.163.6.1391

220. Kitamura M, Takamiya K, Aizawa S, Furukawa K, Furukawa K. Gangliosides are the binding substances in neural cells for tetanus and botulinum toxins in mice. Biochim Biophys Acta (1999) 1441:1-3. doi: 10.1016/S1388-1981(99)00140-7

221. Inoue K, Fujinaga Y, Honke K, Arimitsu H, Mahmut N, Sakaguchi Y, et al. Clostridium botulinum type A haemagglutinin-positive progenitor toxin $(\mathrm{HA}(+)-\mathrm{PTX})$ binds to oligosaccharides containing Gal betal-4GlcNAc through one subcomponent of haemagglutinin (HA1). Microbiology (2001) 147(Pt 4):811-9. doi: 10.1099/00221287-147-4-811

222. Teneberg S, Jurstrand M, Karlsson KA, Danielsson D. Inhibition of nonopsonic Helicobacter pylori-induced activation of human neutrophils by sialylated oligosaccharides. Glycobiology (2000) 10:1171-81. doi: $10.1093 /$ glycob/10.11.1171

223. Roche N, Angstrom J, Hurtig M, Larsson T, Boren T, Teneberg S. Helicobacter pylori and complex gangliosides. Infect Immun. (2004) 72:151929. doi: 10.1128/IAI.72.3.1519-1529.2004

224. Rautelin H, Blomberg B, Fredlund H, Jarnerot G, Danielsson D. Incidence of Helicobacter pylori strains activating neutrophils in patients with peptic ulcer disease. Gut (1993) 34:599-603. doi: 10.1136/gut.34.5.599

225. Nyberg G, Stromberg N, Jonsson A, Karlsson KA, Normark S. Erythrocyte gangliosides act as receptors for Neisseria subflava: identification of the Sia-1 adhesin. Infect Immun. (1990) 58:2555-63.

226. Paruchuri DK, Seifert HS, Ajioka RS, Karlsson KA, So M. Identification and characterization of a Neisseria gonorrhoeae gene encoding a glycolipid-binding adhesin. Proc Natl Acad Sci USA. (1990) 87:333-7. doi: 10.1073/pnas.87.1.333

227. Hugosson S, Angstrom J, Olsson BM, Bergstrom J, Fredlund H, Olcen P, et al. Glycosphingolipid binding specificities of Neisseria meningitidis and Haemophilus influenzae: detection, isolation, and characterization of a binding-active glycosphingolipid from human oropharyngeal epithelium. $J$ Biochem. (1998) 124:1138-52. doi: 10.1093/oxfordjournals.jbchem.a022232

228. Estabrook MM, Zhou D, Apicella MA. Nonopsonic phagocytosis of group C Neisseria meningitidis by human neutrophils. Infect Immun. (1998) 66:102836.

229. Bryan AM, Farnoud AM, Mor V, Del Poeta, M. Macrophage cholesterol depletion and its effect on the phagocytosis of Cryptococcus neoformans. J Vis Exp. (2014) e52432. doi: 10.3791/52432

230. Jimenez-Lucho V, Ginsburg V, Krivan HC. Cryptococcus neoformans, Candida albicans, and other fungi bind specifically to the glycosphingolipid lactosylceramide (Gal beta 1-4Glc beta 1-1Cer), a possible adhesion receptor for yeasts. Infect Immun. (1990) 58:2085-90.

231. Nakayama H, Yoshizaki F, Prinetti A, Sonnino S, Mauri L, Takamori K, et al. Lyn-coupled LacCer-enriched lipid rafts are required for CD11b/CD18mediated neutrophil phagocytosis of nonopsonized microorganisms. $J$ Leukoc Biol. (2008) 83:728-41. doi: 10.1189/jlb.0707478

232. Ladisch S, Wu ZL. Detection of a tumour-associated ganglioside in plasma of patients with neuroblastoma. Lancet (1985) 1:136-8. doi: $10.1016 /$ S0140-6736(85)91906-3

233. Floutsis G, Ulsh L, Ladisch S. Immunosuppressive activity of human neuroblastoma tumor gangliosides. Int $J$ Cancer (1989) 43:6-9. doi: 10.1002/ijc.2910430103

234. Biswas S, Biswas K, Richmond A, Ko J, Ghosh S, Simmons M, et al. Elevated levels of select gangliosides in $\mathrm{T}$ cells from renal cell carcinoma patients is associated with T cell dysfunction. J Immunol. (2009) 183:5050-8. doi: 10.4049/jimmunol.0900259

235. Uzzo RG, Rayman P, Kolenko V, Clark PE, Cathcart MK, Bloom T, et al. Renal cell carcinoma-derived gangliosides suppress nuclear factor-kappaB activation in T cells. J Clin Invest. (1999) 104:769-76. doi: 10.1172/JCI6775

236. Lee HC, Wondimu A, Liu Y, Ma JS, Radoja S, Ladisch S. Ganglioside inhibition of CD8+ $\mathrm{T}$ cell cytotoxicity: interference with lytic granule trafficking and exocytosis. J Immunol. (2012) 189:3521-7. doi: 10.4049/jimmunol.1201256

237. Crespo FA, Sun X, Cripps JG, Fernandez-Botran R. The immunoregulatory effects of gangliosides involve immune deviation favoring type-2 $\mathrm{T}$ cell responses. J Leukoc Biol. (2006) 79:586-95. doi: 10.1189/jlb.0705395

238. Ladisch S, Becker H, Ulsh L. Immunosuppression by human gangliosides: I. Relationship of carbohydrate structure to the inhibition of $\mathrm{T}$ cell responses. Biochim Biophys Acta (1992) 1125:180-8. doi: 10.1016/0005-2760(92)90043-U

239. Chu JW, Sharom FJ. Gangliosides interact with interleukin-4 and inhibit interleukin-4-stimulated helper T-cell proliferation. Immunology (1995) 84:396-403.

240. Lu P, Sharom FJ. Gangliosides are potent immunosuppressors of IL-2mediated T-cell proliferation in a low protein environment. Immunology (1995) 86:356-63.

241. Gomez-Nicola D, Doncel-Perez E, Nieto-Sampedro M. Regulation by GD3 of the proinflammatory response of microglia mediated by interleukin-15. $J$ Neurosci Res. (2006) 83:754-62. doi: 10.1002/jnr.20777

242. Shurin GV, Shurin MR, Bykovskaia S, Shogan J, Lotze MT, Barksdale EM Jr. Neuroblastoma-derived gangliosides inhibit dendritic cell generation and function. Cancer Res. (2001) 61:363-9.

243. Caldwell S, Heitger A, Shen W, Liu Y, Taylor B, Ladisch S. Mechanisms of ganglioside inhibition of APC function. J Immunol. (2003) 171:1676-83. doi: $10.4049 /$ jimmunol.171.4.1676

244. Heitger A, Ladisch S. Gangliosides block antigen presentation by human monocytes. Biochim Biophys Acta (1996) 1303:161-8. doi: 10.1016/0005-2760(96)00091-4

245. Hoon DS, Jung T, Naungayan J, Cochran AJ, Morton DL, McBride WH. Modulation of human macrophage functions by gangliosides. Immunol Lett. (1989) 20:269-75. doi: 10.1016/0165-2478(89)9 0034-5 
246. Grayson G, Ladisch S. Immunosuppression by human gangliosides. II Carbohydrate structure and inhibition of human NK activity. Cell Immunol. (1992) 139:18-29. doi: 10.1016/0008-8749(92)90096-8

247. Fujimaki H, Nohara O, Katayama N, Abe T, Nohara K. Ganglioside GM3 inhibits interleukin-3-dependent bone marrow-derived mast cell proliferation. Int Arch Allergy Immunol. (1995) 107:527-32. doi: $10.1159 / 000237095$

248. Yoon HJ, Jeon SB, Suk K, Choi DK, Hong YJ, Park EJ. Contribution of TLR2 to the initiation of ganglioside-triggered inflammatory signaling. Mol Cells (2008) 25:99-104.

249. Cheever MA, Allison JP, Ferris AS, Finn OJ, Hastings BM, Hecht TT, et al. The prioritization of cancer antigens: a national cancer institute pilot project for the acceleration of translational research. Clin Cancer Res. (2009) 15:5323-37. doi: 10.1158/1078-0432.CCR-09-0737

250. Yvon E, Del Vecchio M, Savoldo B, Hoyos V, Dutour A, Anichini $A$, et al. Immunotherapy of metastatic melanoma using genetically engineered GD2-specific T cells. Clin Cancer Res. (2009) 15:5852-60. doi: 10.1158/1078-0432.CCR-08-3163

251. Prapa M, Caldrer S, Spano C, Bestagno M, Golinelli G, Grisendi G, et al. A novel anti-GD2/4-1BB chimeric antigen receptor triggers neuroblastoma cell killing. Oncotarget (2015) 6:24884-94. doi: 10.18632/oncotarget.4670

252. Thomas S, Straathof K, Himoudi N, Anderson J, Pule M. An optimized GD2-targeting retroviral cassette for more potent and safer cellular therapy of neuroblastoma and other cancers. PLoS ONE (2016) 11:e0152196. doi: 10.1371/journal.pone.0152196

253. Lo AS, Ma Q, Liu DL, Junghans RP. Anti-GD3 chimeric sFv-CD28/Tcell receptor zeta designer $\mathrm{T}$ cells for treatment of metastatic melanoma and other neuroectodermal tumors. Clin Cancer Res. (2010) 16:2769-80. doi: 10.1158/1078-0432.CCR-10-0043

254. Ponath P, Menezes DL, Pan C, Chen B, Oyasu M, Strachan D, et al. A novel, fully human anti-fucosyl-GM1 antibody demonstrates potent in vitro and in vivo antitumor activity in preclinical models of small cell lung cancer. Clin Cancer Res. (2018) 24:5178-89. doi: 10.1158/1078-0432.CCR-18-0018

255. Durrant LG, Noble P, Spendlove I. Immunology in the clinic review series; focus on cancer: glycolipids as targets for tumour immunotherapy. Clin Exp Immunol. (2012) 167:206-15. doi: 10.1111/j.1365-2249.2011.04516.x

256. Buskas T, Thompson P, Boons GJ. Immunotherapy for cancer: synthetic carbohydrate-based vaccines. Chem Commun. (2009) 36:5335-49. doi: 10.1039/b908664c

257. Karlsson GB, Butters TD, Dwek RA, Platt FM. Effects of the imino sugar Nbutyldeoxynojirimycin on the N-glycosylation of recombinant gp 120. J Biol Chem. (1993) 268:570-6.

258. Platt FM, Neises GR, Dwek RA, Butters TD. N-butyldeoxynojirimycin is a novel inhibitor of glycolipid biosynthesis. J Biol Chem. (1994) 269:8362-5.

259. Platt FM, Butters TD. New therapeutic prospects for the glycosphingolipid lysosomal storage diseases. Biochem Pharmacol. (1998) 56:421-30.

260. Radin NS. Chemotherapy by slowing glucosphingolipid synthesis. Biochem Pharmacol. (1999) 57:589-95.

261. Inokuchi J, Mason I, Radin NS. Antitumor activity via inhibition of glycosphingolipid biosynthesis. Cancer Lett. (1987) 38:23-30. doi: 10.1016/0304-3835(87)90196-0

262. Ersek A, Xu K, Antonopoulos A, Butters TD, Santo AE, Vattakuzhi $\mathrm{Y}$, et al. Glycosphingolipid synthesis inhibition limits osteoclast activation and myeloma bone disease. J Clin Invest. (2015) 125:2279-92. doi: 10.1172/JCI59987

263. Liu YY, Hill RA, Li YT. Ceramide glycosylation catalyzed by glucosylceramide synthase and cancer drug resistance. Adv Cancer Res. (2013) 117:59-89. doi: 10.1016/B978-0-12-394274-6.00003-0
264. Wegner MS, Gruber L, Mattjus P, Geisslinger G, Grosch S. The UDP-glucose ceramide glycosyltransferase (UGCG) and the link to multidrug resistance protein 1 (MDR1). BMC Cancer (2018) 18:153. doi: 10.1186/s12885-018-4084-4

265. Tierney M, Pottage J, Kessler H, Fischl M, Richman D, Merigan T, et al. The tolerability and pharmacokinetics of N-butyl-deoxynojirimycin in patients with advanced HIV disease (ACTG 100). The AIDS Clinical Trials Group (ACTG) of the National Institute of Allergy and Infectious Diseases. J Acquir Immune Defic Syndr Hum Retrovirol. (1995) 10:549-53. doi: 10.1097/00042560-199510050-00008

266. Venier RE, Igdoura SA. Miglustat as a therapeutic agent: prospects and caveats. J Med Genet. (2012) 49:591-7. doi: 10.1136/jmedgenet-2012-101070

267. Cox T, Lachmann R, Hollak C, Aerts J, van Weely S, Hrebicek M, et al. Novel oral treatment of Gaucher's disease with N-butyldeoxynojirimycin (OGT 918) to decrease substrate biosynthesis. Lancet (2000) 355:1481-5. doi: 10.1016/S0140-6736(00)02161-9

268. Heitner R, Elstein D, Aerts J, Weely S, Zimran A. Low-dose Nbutyldeoxynojirimycin (OGT 918) for type I Gaucher disease. Blood Cells Mol Dis. (2002) 28:127-33. doi: 10.1006/bcmd.2002.0497

269. Elstein D, Hollak C, Aerts JM, van Weely S, Maas M, Cox TM, et al. Sustained therapeutic effects of oral miglustat (Zavesca, N-butyldeoxynojirimycin, OGT 918) in type I Gaucher disease. J Inherit Metab Dis. (2004) 27:757-66. doi: 10.1023/B:BOLI.0000045756.54006.17

270. Narimatsu Y, Joshi HJ, Yang Z, Gomes C, Chen YH, Lorenzetti FC, et al. A validated gRNA library for CRISPR/Cas9 targeting of the human glycosyltransferase genome. Glycobiology (2018) 28:295-305. doi: 10.1093/glycob/cwx101

271. Seki A, Rutz S. Optimized RNP transfection for highly efficient CRISPR/Cas9-mediated gene knockout in primary T cells. J Exp Med. (2018) 215:985-97. doi: 10.1084/jem.20171626

272. Wu CM, Roth TL, Baglaenko Y, Ferri DM, Brauer P, Zuniga-Pflucker JC, et al. Genetic engineering in primary human B cells with CRISPRCas9 ribonucleoproteins. J Immunol Methods (2018) 457:33-40. doi: 10.1016/j.jim.2018.03.009

273. Li Y, Teneberg S, Thapa P, Bendelac A, Levery SB, Zhou D. Sensitive detection of isoglobo and globo series tetraglycosylceramides in human thymus by ion trap mass spectrometry. Glycobiology (2008) 18:158-65. doi: 10.1093/glycob/cwm129

274. Li Y, Zhou D, Xia C, Wang PG, Levery SB. Sensitive quantitation of isoglobotriaosylceramide in the presence of isobaric components using electrospray ionization-ion trap mass spectrometry. Glycobiology (2008) 18:166-76. doi: 10.1093/glycob/cwm 127

275. Anugraham M, Everest-Dass AV, Jacob F, Packer NH. A platform for the structural characterization of glycans enzymatically released from glycosphingolipids extracted from tissue and cells. Rapid Commun Mass Spectrom. (2015) 29:545-61. doi: 10.1002/rcm.7130

Conflict of Interest Statement: The authors declare that the research was conducted in the absence of any commercial or financial relationships that could be construed as a potential conflict of interest.

Copyright (c) 2019 Zhang, de Waard, Wuhrer and Spaapen. This is an open-access article distributed under the terms of the Creative Commons Attribution License (CC $B Y)$. The use, distribution or reproduction in other forums is permitted, provided the original author(s) and the copyright owner(s) are credited and that the original publication in this journal is cited, in accordance with accepted academic practice. No use, distribution or reproduction is permitted which does not comply with these terms. 